\title{
Remote sensing contributing to assess earthquake risk From a literature review towards a roadmap
}

\author{
Christian Geiß $\cdot$ Hannes Taubenböck ${ }^{1}$
}

\begin{abstract}
Remote sensing data and methods are widely deployed in order to contribute to the assessment of numerous components of earthquake risk. While for earthquake hazard related investigations the use of remotely sensed data is an established methodological element with a long research tradition, earthquake vulnerability centered assessments incorporating remote sensing data are increasing primarily in recent years. This goes along with a changing perspective of the scientific community which considers the assessment of vulnerability and its constituent elements as a pivotal part of a comprehensive risk analysis. Thereby, the availability of new sensors systems enables an appreciable share of remote sensing first. In this manner, a survey of the interdisciplinary conceptual literature dealing with the scientific perception of risk, hazard and vulnerability reveals the demand for a comprehensive description of earthquake hazards as well as an assessment of the present and future conditions of the elements exposed. A review of earthquake related remote sensing literature, realized both in a qualitative and quantitative manner, shows the already existing and published manifold capabilities of remote sensing contributing to assess earthquake risk. These include earthquake hazard related analysis such as detection and measurement of lineaments and surface deformations in pre- and post-event applications. Furthermore, pre-event seismic vulnerability centered assessment of the built and natural environment and damage assessments for post-event applications are presented. Based on the review and the discussion of current scientific foci and research projects first steps towards a roadmap for remote sensing is drawn, explicitly taking scientific, technical, multi- and transdisciplinary as well as political perspectives into account, which is intended to open possible future research activities.
\end{abstract}

Keywords Remote Sensing · Earthquake $\cdot$ Risk $\cdot$ Hazard $\cdot$ Vulnerability $\cdot$ Literature Review $\cdot$ Roadmap

Christian Geiß · Hannes Taubenböck

German Aerospace Center (DLR), German Remote Sensing Data Center (DFD),

Oberpfaffenhofen, 82234 Weßling, Germany

e-mail: christian.geiss@dlr.de; hannes.taubenboeck@dlr.de 


\section{Introduction}

According to official estimates the magnitude 7.0 earthquake in Haiti in 2010 killed 316,000 people, 300,000 were injured and 1.3 million people were displaced, 97,294 houses were destroyed and further 188,383 damaged (USGS 2011). Other prominent examples of the last decennium are the earthquakes in Eastern Sichuan in China in 2008 (87,587 casualties), in Pakistan in 2005 (86,000 casualties) or in Bam in Iran in 2003 (30,000 casualties). These immense figures emphasise the devastating impact of earthquakes, especially in countries that are not prepared for such an event. In 2008 e.g. the NatCatSERVICE of the Munich Re's database on natural hazards documented 750 loss events, with only $12 \%$ from earthquakes (Munich Re Group 2011). However, in the same year $43 \%$ of all fatalities and $43 \%$ overall economic losses around the globe were caused by earthquakes.

In general, urban populations are expected to be killed by earthquakes in the foreseeable future in greater numbers than in the documented past (Bilham 2009). Many hot spots for devastating future earthquakes are known and well documented (Dilley et al. 2005). For instance the mega city Istanbul, Turkey, with its estimated 15 million inhabitants is threatened by a $30-70 \%$ probability of a major earthquake $\left(\mathrm{M}_{\mathrm{w}}>7\right)$, in the next 30 years (Parsons 2004).

However, "the international community's response to disasters has been mostly reactive, with only limited budget invested in prevention. (. . .) Even if there were a willingness to invest in prevention, the question would be: where?" (Peduzzi 2006: 171).

Prior to this question, the concept of risk itself is subject to a vibrant debate within the scientific community, which constitutes an alteration of the perception of risk. While hazardoriented research strategies dominated the past (Lewis 1999; Zhang et al. 2002), more integrative approaches to assess risk and its components, incorporating also human, societal and cultural factors, are in the focus of the scientific community nowadays (Turner et al. 2003; Pelling 2003; Cardonna 2004; Adger 2006; Birkmann 2006b; Thywissen 2006; Mercer et al. 2007; Fuchs 2009). This shift is based on the realization that natural hazards do not have an intrinsic dangerous character itself (Cannon 1994; Wisner 2007), but become disastrous if an unfavourable combination of several parameters comes together. In this regard, natural disasters are perceived as "un-natural" (O'Keefe et al. 1976; WB/UN 2010), not solely triggered by natural events but also connected to social, economic, ecological, social and political aspects (Burton et al. 1993; Blaikie et al. 1994; Alexander 2002; Schneiderbauer \& Ehrlich 2004; Smith \& Petley 2009). Therefore, disasters can be viewed as a consequence of a complex reciprocity between potentially damaging physical events such as earthquakes, tsunamis, droughts, floods, storms etc. and the vulnerability of the built and natural environment, society, and economy, which are preconditioned by human behaviour (Birkmann 2006b) and often constitute and manifest development problems (UN 1994; Yodmani 2001; Alcantara-Ayala 2002; Guinau et al. 2005; Schneiderbauer \& Ehrlich 2006). To consider these framing conditions for disaster management and develop strategies to reduce disaster risk, several integrative research concepts have been designed and postulated (e.g. Cutter 1996; Turner et al. 2003; Wisner et al. 2003; Bogardi \& Birkmann 2004). Still, there is a lack within the scientific community concerning common ontologies and definitions (Hufschmidt 2011) especially about terms like 'risk' and 'vulnerability' (Timmermann 1981; Cutter 2003; Thywissen 2006). This is mainly due to an inflationary usage of those terms within several research contexts and scientific disciplines (Cutter 1996) and the need to work in the context of different social and environmental conditions (Hufschmidt 2011).

In order to be able to categorize and discuss the role of remote sensing against this framing background of risk, this article gives a multidisciplinary overview of concepts and definitions and the associated theoretical assumptions and implications first. 
Despite this divergence about basic terminological questions there is an increasing convergence about the need for robust and reliable indicators and methods to identify and assess risk and its components and utilize that information to reduce disaster risk (Kasperson et al. 2005; Villagrán De Léon 2006; Birkmann 2006b; Peduzzi et al. 2009; Heltberg et al. 2009). It has been stated numerous times, that one of the most difficult issues in assessing risk is the gathering of appropriate data (Birkmann 2006a; Ehrlich \& Zeug 2008; Ehrlich et al. 2010), In this manner, remote sensing is perceived as promising tool for an economical, up-to date and area-wide information collection in general (Dech 1997; Paylor II et al. 2005; Mueller et al. 2006; French \& Muthukumar 2006; Chiroiu et al. 2006; Esch et al. 2009; Joyce et al. 2009a; Guo 2010). In particular, previous studies demonstrated that remote sensing is able to tackle certain aspects of earthquake risk. These reach from hazard related analyses (e.g. Fu et al. 2004; Stramondo et al. 2005; Philip 2010) to vulnerability centered assessments (e.g. Taubenböck et al. 2008, 2009a; Ehrlich et al. 2010; Deichmann et al. 2011).

Thus, the second research target of this article is to identify and discuss these potentials, and at the same time show limitations of remote sensing contributing to assess earthquake risk.

From a temporal perspective, remote sensing contributions to assess earthquake risk have a long research tradition. Remote sensing imagery is already used for hazard related applications since the advent of satellite systems and sensors four decades ago (Tronin 2010). However, especially for vulnerability related analysis remote sensing is a less established methodological element (Nassel \& Voigt 2006) and is perceived increasingly only in recent years as a valuable source of information (Deichmann et al. 2011).

In order to disclose such developments and identify general trends, a quantitative analysis of the literature is performed reaching from 2011 back to 1991, which is completed by presenting actual research foci and initiatives in Sect. 4.

Finally, based on the previous chapters as well as on experiences in projects, advisory boards, at conferences and interviews with experts a synthesis is given in Sect. 5, which addresses explicitly scientific, technical, multi- and transdisciplinary and political perspectives in order to propose possible future research.

The structure of this paper is visualized in Fig. 1, which shows the aggregated content of the respective sections.

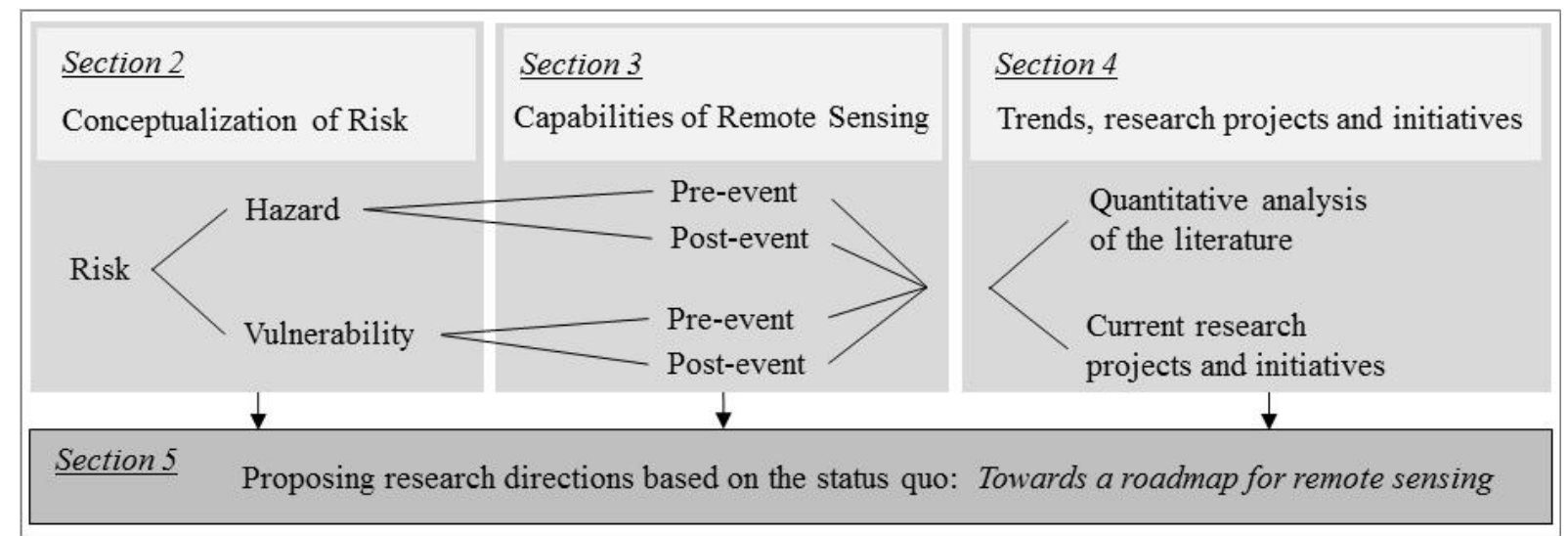

Fig. 1 Structure and content of the paper

\section{Conceptualization of risk}

From a very general perspective, risk can be described as probability to suffer loss, damage and negative consequences (Burby 1991; Brooks 2003), referred to a present or specified 
future time period (Lafond \& Gosselin 1994; Coburn et al. 1994). Projected to the context of disaster and risk management the probability of harmful consequences or expected losses is explicitly linked to the influence of a particular hazard for a given area (Downing et al. 2001) to a given element at danger or peril (Schneiderbauer \& Ehrlich 2006). However, risk cannot solely be characterized as a function of a hazard, describing the possibility of physical harm, since elements exposed to a certain hazard can react differently in order of their degree of vulnerability, or resilience respectively, if understood as antonym of vulnerability (Adger et al. 2005), and therefore modify the realisation of risk (Cannon 1993; Chapman 2001; Schneiderbauer \& Ehrlich 2004; Samuels et al. 2009). In this manner, the risk for a particular system (e.g. city) can be described on the basis of two distinctive factors: (i) A potentially damaging event, phenomenon or human activity, which is constituted by likelihood of occurrence, intensity, frequency and location and (ii) the vulnerability, which characterizes the degree of susceptibility of the element exposed to that particular source and therefore manifest the relationship of the degree of exposure and the degree of damage (UN/ISDR 2004). This conceptual superstructure of risk is very prevalent within the scientific community (Wisner et al. 2003; Birkmann 2007), deployed in various theoretical and conceptual approaches and applications (e.g. Blaikie et al. 1994; Garatwa and Bollin 2002; Bollin 2003; Rashed and Weeks 2003; Sarewitz et al. 2003; UN/ISDR 2004; Taubenböck et al. 2008; Müller et al. 2011). Birkmann (2006b, 2007) reveals that the hazard event is primarily perceived as an external factor (see also van Dillen 2004), while the term vulnerability describes the intrinsic characteristics of a system (Bohle 2001). However, there are several definitions that adapt this separation of hazard and vulnerability, but divide the vulnerability part in further subcomponents (White et al. 2005; Villagrán De Léon 2006). A definition which is exhaustively used by the earthquake disaster risk community denotes elements at risk, which are understood as objects potentially adversely affected such as people, properties, infrastructure or economic activities, as autonomous component (UNDRO 1979; Crichton 1999; Granger 2003; Masure 2003; Schneiderbauer \& Ehrlich 2004; Peduzzi et al. 2005; Sinadinovski et al. 2005; Dilley et al. 2005; UNDP/ERRRP 2009; Ehrlich et al. 2010; Deichmann et al. 2011). Thereby, the calculation of potential losses within frameworks of earthquake risk models such as HAZUS (FEMA 2010), OpenQuake (GEM 2011) or RiskScape (RiskScape 2012) is carried out by combining determined hazard parameters, quantified and characterized exposed elements and their assessed vulnerability. However, there are also definitions which put vulnerability in a less broader context and therefore explicitly address within the risk definition components like e.g. resilience (Thywissen 2006), deficiencies in preparedness (Villagrán De Léon 2006), or coping capacities (Davidson 1997; Hahn 2003) separately.

In contrast, especially definitions and concepts evolved from global environmental and climate change research do not follow the separation of hazard and vulnerability (Cutter 1996; Füssel \& Klein 2006), but take the hazard and the exposure to it into account by considering anthropogenic actions, which indeed are effecting the environment and therefore some of the hazards (Villagrán De Léon 2006). However, we maintain the conceptual superstructure of the (UN/ISDR 2004) definition, since we focus on earthquake hazards, that are beyond the influence of human kind (Bollin 2003) and discuss different perspectives on risk components at the respective passage. For overviews of risk definitions with respect to different scientific disciplines the reader is referred to e.g. Brooks 2003, Schneiderbauer \& Ehrlich 2004, and Thywissen 2006. Carreno et al. (2007) provide an introductory chronological description of the development of epistemological terms und concepts in the context of earthquake risk. In conclusion, according to Deichmann et al. (2011), it should be noted that all components of natural disaster risk show an inherent variability over space and therefore risk identification and assessment must rely on data and information with spatial reference. 


\subsection{Hazard}

Based on a wider understanding, hazards represent potentially damaging events, phenomenon or human activities, which may have negative consequences on human aspects (loss of life or injury), elements of the built environment (property damage) and environmental components. Hazards can be single, sequential or combined, both in their origin and effects (UN/ISDR 2004). For example earthquakes may trigger other earthquakes (e.g. Pinar et al. 2001; Erdik et al. 2004; McCloskey et al. 2005; Marsan \& Lengline 2008) and/or secondary effects such as landslides (e.g. Bommer \& Rodriguez 2002; Huang \& Li 2009), tsunamis (e.g. Sahal et al. 2009; Taubenböck et al. 2009b; Rosenau et al. 2010; Strunz et al. 2011) or fires (e.g. Girgin 2011), also in a cascading way (Schneiderbauer \& Ehrlich 2004), that can even be more disastrous than the initial hazard (Korup 2010).

Brooks (2003) notes, that in certain definitions there is some ambiguity as to whether hazards represent a trigger event or the outcome of such events. Schneiderbauer \& Ehrlich (2004) state that especially in the disaster related literature there are divergent views whether hazards should only describe naturally induced events or also include events which are triggered by human activities. In this context, Garatwa \& Bollin (2002) make a distinction between real natural hazards such as earthquakes, volcanic eruptions and storms and socio-natural hazards such as floods, droughts and forest fires, which are also caused or exacerbate due to human intervention in nature. Analogous, Smith \& Petley (2009) show the spectrum of environmental hazards reaching from geophysical events to human activities, where hazards with a high level of human causation such as air pollution, industrial accidents or bushfires are more voluntary in terms of their acceptance and more diffuse in terms of their disaster impact in contrast to highly involuntary hazards such as earthquakes, tsunamis, etc. As already mentioned above, Schneiderbauer \& Ehrlich (2006) emphasize that hazards often have interrelated causes and therefore the allocation of a hazard to one class may be difficult. However, if describing certain hazard-related risk components that are at the same time most likely hazard-specific (Brooks 2003), it is crucial to determine basic characteristics such as magnitude (only events are considered as extreme, when some common level is exceeded), duration (persistence of a hazardous event), speed of onset (time between first occurrence of an event and its peak), temporal spacing (sequencing of events ranging from random to periodic), spatial extent (space covered by a hazardous event) and spatial dispersion (pattern of distribution over the space the impact can occur) (Gravely 2001, quoted in Schneiderbauer \& Ehrlich 2004).

In this regard, earthquake hazards are typically characterized based upon the basic concepts of probabilistic seismic hazard assessment (Cornell 1968) and described by probabilities of occurrence of earthquakes with a specified amplitude of interest for a given period of time (Robinson et al. 2006; UNDP/ERRRP 2009; see Panza et al. 2011 for a critical discussion of the shortcomings of this method). In order to describe potential earthquake hazards, Sinadinovski et al. (2005) distinguish between regional seismic models (description of the chance of an earthquake of a given magnitude occurring in a specified time period in various parts of the region), attenuation models (general description how earthquake ground shaking or intensity decreases with distance away from the earthquake source) and site response models (description how local soil conditions will affect the ground shaking experienced during an earthquake). In detail, a pre-event earthquake parameter evaluation may include earthquake intensity, peak velocity, predominant period, potential earthquake source, liquefaction potential etc. and also take the analyses of potential secondary threats into account (Tang \& Wen 2009) based on empirical, analytical or hybrid methods (e.g. Calvi et al. 2006; Crowley \& Bommer 2006). 


\subsection{Vulnerability}

An international wide spread definition of vulnerability in the context of risk research describes vulnerability as "the conditions determined by physical, social, economic and environmental factors or processes, which increase the susceptibility of a community to the impact of a hazard" (UN/ISDR 2004). Although this definition provides little information about the specific factors or processes that constitute vulnerability, it is clear that vulnerability characterizes the combined conditions and situations of various elements of interest, that make them prone being affected from the influences of an hazardous event (Bogardi et al. 2005; Birkmann et al. 2011). Vulnerability has to be understood as a predictive concept, since vulnerability is a present attribute that describes and characterizes possible future harm (Wolf 2011). Certainly, it should also be noted that within vulnerability research different schools of thought exist with partially significant differences regarding definitions and associated concepts (Birkmann et al. 2011; see also Birkmann 2006b; Füssel \& Klein 2006; Thywissen 2006), since vulnerability is perceived basically as something abstract without a simple, clear notion (Hilhorst \& Bankoff 2004). However, Wolf (2011) argues, that especially from a methodological point of view, which incorporates certain strategies to assess vulnerability, these differences are less conceptual but primarily terminological.

The concept of vulnerability emerged within the social sciences as a reaction to a solely hazard oriented reception of disasters and risk in the early 1970s (Schneiderbauer \& Ehrlich 2004; Villagrán De Léon 2006). But already Timmermann (1981) stressed the heterogenic definitions of that term, which made it almost useless for a careful description. Bogardi \& Birkmann (2004) note, that vulnerability does not represent a clear scientific concept, what causes the paradox that the scientific community tries to measure vulnerability, but cannot define it precisely yet (Birkmann 2006b). Rashed \& Weeks (2003) state, that assessing vulnerability and risk towards natural hazards can be regarded as an ill-structured problem, without a unique, clearly identifiable and objectively optimal solution. Therefore it is no surprise that within the actual scientific literature numerous definitions and pre-analytic frameworks have emerged, assigning a definition with respect to a specific epistemological view of several research disciplines (Wisner 2004; Brooks 2003) and enhance it with individual connotations in order to make the term operable for different research question. An overview of several definitions can be studied e.g. in Schneiderbauer \& Ehrlich (2004), Green (2004), Thywissen (2006), Villagrán De Léon (2006), Adger (2006), Fuchs (2009), and Cutter et al. (2009). Kasperson et al. (2005) and Füssel (2007) provide an overview of the evolution of concepts and approaches to vulnerability research, respectively.

Within the social sciences vulnerability refers to the susceptibility of a given population or social system to harm from exposure to multiple stressors (Alwang et al. 2001). It is directly linked to the ability to prepare for, respond to, and recover from hazards and disasters. Social vulnerability therefore explicitly focuses on demographic and socioeconomic factors (Briuglio 1995) that increase or attenuate the impacts of hazard events on local populations (Cutter et al. 2009). The perspective of numerous definitions and concepts are human-centred (Bohle et al. 1994; Adger et al. 2001; Cannon et al. 2003), incorporating the role of human agency explicitly by attributing the driving forces of vulnerability on the social, political, and economic pressures imposed on individuals, which constrain their responses and ability to cope with disasters (Forsyth 2004; Adger 2006; Walton et al. 2008). In this manner, Wisner (2004) tracks the progression of vulnerability from root causes to dynamic pressures to unsafe conditions, which then interact with natural events. Bohle (2001) emphasizes the double structure of vulnerability with an external and internal side, whereas the external side includes the exposure to potentially damaging events and the internal side relates to the capacity to cope with, resist and recover from the impact of a hazard. Viewed from these perspectives, 
vulnerability depends almost as much on the preparedness and coping capacity of the affected society as on the natural hazards itself (Bogardi \& Birkmann 2004).

Within the natural sciences, the focus is on physical damage assessment and related adaption processes, where vulnerability of a given entity (system, sector, region etc.) may tentatively be defined as the expected damage resulting from anticipated environmental perturbations in consideration of the expected transformation and adaption processes (Corell et al. 2001). For example, the "end point" definition of Bogardi et al. (2005) views vulnerability as the residual segments of natural impacts that cannot be targeted by adaption processes. In this context, adaption based approaches explicitly consider the examination of the adaptive capacity (O'Brien et al. 2004), which is necessary to improve the resilience and robustness of a certain system (Smit \& Wandel 2006). Therefore, the framework presented by Turner et al. (2003) sets vulnerability in context of a human-environmental system with multiple perturbations and stresses, encompassing exposure, sensitivity and resilience as discrete but interlinked components of vulnerability.

Definitions and approaches evolved from disaster management, concentrate upon potentials of the population to overcome and recover from the impact of a hazard (IFRC 1999). Blaikie et al. (1994) define vulnerability with respect to this kind of perspective as characteristics of a person or group in terms of their capacity to anticipate, cope with, resist and recover from the impact of a natural hazard. Furthermore it involves a combination of factors that determine the degree to which someone's life and livelihood are put at risk by a discrete and identifiable event in nature or in society. Therefore, Schneiderbauer \& Ehrlich (2006) state that the focus of disaster management research also shifted from "hazard assessment" to "vulnerability analysis".

However, approaches evolved from engineering sciences mainly concentrate upon short-term intensive extern influences on certain valued elements (e.g. buildings) and their related susceptibility by defining vulnerability as the severity of failure in terms of its consequences (Coburn et al. 1994; Burton et al. 1993). The concern is not how long the failure lasts but how costly it is (Correira et al. 1987). From this point of view, vulnerability can e.g. be quantified by deriving an empirical relation between number of affected people and impact of a natural hazard (Vrijling et al. 1995). Especially within the engineering focused earthquake risk community (Smith 2005), vulnerability is linked to the probability of collapse of buildings and critical lifelines considering specific earthquake scenarios and taking potential human casualties and economic losses into account (Menoni et al. 2002; Sinadinovski et al. 2005). Based on damage assessment approaches (Whitman 1973), methodologies are developed that focus on physical components of seismic vulnerability. For instance, an assessment of damage for loss estimation studies combines parameters that are hazard related such as the determination of macro seismic intensity and peak ground acceleration with the analysis of the seismic vulnerability of built up structures by methods such as displacement response spectra (Crowley et al. 2004) or capacity spectrum (Freeman 2004), depending on conceptual assumptions whether a single building is studied in detail or idealized classes of buildings are considered for scenario-oriented analyses (Calvi 1999). In this regard, the likely damage to structures is modelled by expressing their vulnerability by damage functions and fragility curves (Robinson et al. 2006; FEMA 2010). Seismic loss is therefore described as a function of exposure, which is represented by the amount of human activity at a certain location (e.g. stock of infrastructure), vulnerability, which describes the susceptibility of the infrastructure stock, the hazard, which is expressed by the likelihood of occurrence of a specified ground motion at a certain location and damage loss conversion, which refers to the mean damage ratio (Crowley et al. 2006, quoted in Daniell 2009; Daniell 2011).

Yet, integrative approaches e.g. incorporating human, financial, social and administrative aspects for describing earthquake effects (Coburn \& Spence 1992) are established, reaching wide spread methodologies such as HAZUS-MH (FEMA 2010), where also multi hazard risk 
assessments are considered (Carreno et al. 2007). More extensively, Cardona (1999) developed a holistic approach evaluating disaster risk, where exposed elements are assessed in dependence of several aspects and dimensions of vulnerability. Vulnerability is therefore characterized based upon exposure and physical susceptibility, which is hazard dependent, as well as social and economic fragilities and lack of resilience or ability to cope and recover, which both are considered as hazard independent (Cardona \& Hurtado 2000). By overlaying and weighting normalized risk parameters that may come from a multidisciplinary perspective, earthquake risk is spatially expressed in a commensurable way aiming at an holistic view (Carreno et al. 2007; Carreno et al. 2009a; Carreno et al. 2009b).

Adapting this holistic perspective, Birkmann (2006b) stresses that vulnerability should not be viewed as an isolated feature, but can be embedded within the context of a dynamic process, which implies that the focus has simultaneously be on vulnerabilities, coping capacities and intervention tools in order to reduce vulnerability. Thywissen (2006) reveals that within earthquake engineering the susceptibility is often quantified by means of a damage ratio but especially intangible parameters related to e.g. environmental, institutional or human factors, which can often hardly be quantified properly, are set aside.

However, all of the presented multidisciplinary definitions and concepts have the core notion "potential for disruption or harm" in common (Wisner 2004) and connect a specified system (e.g. region, social group, sector) with risk (Füssel 2005), respectively. This perspective implies that the present and future conditions of the elements exposed can be viewed as the central elements of vulnerability (UNDP 2004; Cardona 2004; Thywissen 2006), whereby the impacts as well as the receptors of natural hazards are considered (Fuchs et al. 2011).

\section{Capabilities of Remote Sensing in order to Assess Earthquake Risk}

Generally, remote sensing techniques are widely deployed for contributing to numerous aspects of earthquake risk. They provide valuable information for both hazard and vulnerability related research.

Regarding the disaster management cycle, that can be split in four phases (Cartwright 2005), including pre-event phases such as reduction (mitigation) and readiness (preparedness), as well as post-event phases such as response and recovery, remote sensing has a numerous share in each of it (Joyce et al. 2009a). As already described, secondary effects of an earthquake such as tsunamis, landslide, fires etc. are a critical part of a comprehensive and integrative risk assessment (Deichmann et al. 2011). However, in this review, only risk components which are directly related to earthquakes are considered. For remote sensing literature contributing to secondary effects the reader is referred to e.g. Roessner et al. (2005), Hong et al. (2007), and Han et al. (2009) regarding landslides, Yamazaki \& Matsuoka (2007), and Pesaresi et al. (2007) with respect to tsunamis, or Gitas et al. (2008) contributing to fire hazards.

\subsection{Hazard Parameters}

Remote sensing for earthquake hazard research evolved simultaneously to the first appearance of commercially available satellite images in the 1970ies, which were used to map active faults and structures (Tronin 2006). Nowadays, applications contributing to the understanding and documentation of location, slip rates as well as the kinematics and dynamics of active 
faults on interseismic temporal scales are based on a wide spectrum of air- and spaceborne remote sensing reaching from optical sensors to radar systems (Tralli et al. 2005).

\subsubsection{Pre-Event}

Several aspects of pre-event earthquake hazard analysis are tackled by means of remotely sensed data. Especially in pre-event geological observations remote sensing addresses the need for quantitative observational parameters on landforms, land cover and tectonic features (Philip 2010). Deichmann et al. (2011) note that remote sensing can contribute valuable information for microscale zonation by deriving information for producing geological, seismic or soil maps. Thereby, DSMs and multispectral imagery proved to be a valuable data source for a detailed, spatially consistent and thematically suitable site characterization (Yong et al. 2008a, 2008b, Shafique et al. 2012). In this manner, Theilen-Willige (2010), Reif et al. (2011), and Shafique et al. (2011) analyse geomorphologic/topographic features and settings of earthquake hazard prone areas by extracting geomorphometric/seismotectonic parameters based on DEM data, whereas e.g. Sitharam et al. (2006), Demirkesen (2008), or Duarah \& Phukan (2011) also incorporate multispectral imagery for terrain analysis and the description of lineaments. Based on DEMs derived from LiDAR surface expression of faulting can be mapped with a high accuracy and detail (Cunningham et al. 2006; Begg \& Mouslpoulou 2007). By integrating optical data (Walker 2006; Kaya et al. 2004; Gonzalez et al. 2010) and DEMs derived from stereoscopic imagery (Fu et al. 2004), active faults can be mapped less detailed but for a larger spatial extent.

By using multitemporal SAR data, pre-seismic land surface deformations even in the amount of centimetres can be measured based on concepts and techniques of differential interferometric SAR (D-InSAR) (Kuzuoka \& Mizuno 2004; Stramondo et al. 2007; Bayuaji et al. 2010). Weston et al. (2012) compare earthquake source models determined by InSAR and seismic data and find InSAR to be a valuable technique for the estimation of earthquake source parameters such as location, seismic moment, fault geometry etc. This technique has proven to be advantageous compared to e.g. GPS-based measurements in terms of costs, coverage, and data accessibility (Fornaro et al. 2009) and is used in order to evaluate the seismic potential of a region (Yen et al. 2008), quantify aseismic accumulation of strains between events (Fielding et al. 2004), and calculate slip-rates of segments (Ding \& Huang 2011), what also possibly allows to identify precursory surface deformations (Tsai et al. 2006). In this manner, Tralli et al. (2007) present a conceptual case for the assimilation of InSAR measurements into the HAZUS-MH earthquake module.

Based on data from thermal sensors, short-term temperature increases prior to several earthquake events have been described numerous times for both surface and atmosphere (Gorny et al. 1988; Tronin 1996; Ouzounov \& Freund 2004; Saraf \& Choudhury 2005; Ouzounov et al. 2006; Choudhury et al. 2006; Yurur 2006; Ouzounov et al. 2007; Yang \& Guo 2010; Saradjian \& Akhoondzadeh 2011; Chen et al. 2011), what may hold information for earthquake prediction and warning (see also Saraf et al. (2009) for a discussion of reasons of correlation of these phenomena). Also, other anomalies related to earthquakes that can be detected by remote sensing instruments are discussed in the literature (Tronin 2010) such as ionospheric (Kakinami et al. 2010) or cloud (Gup \& Xie 2007) anomalies.

\subsubsection{Post-Event}

Post-event hazard related applications deal mainly with the quantification and measurement of earthquake induced changes of the land surface. Takano \& Maeda (2009) and Maeda \& Takano (2010) present an approach to detect land-surface deformation induced by earthquakes based on spaceborne microwave radiometer data with a high timely resolution. 
Lineament analysis based on pre- and post-event optical data have shown significant changes in terms of number, spatial distribution and arrangement (Arellano-Baeza et al. 2006; Liu \& Haselwimmer 2006). Coseismic effects of strong earthquakes can cause gravity pertubations, which are detectable by spaceborne sensors dedicated to gravity field measurements (Tralli et al. 2005). For instance, the GRACE (Gravity Recovery and Climate Experiment) satellites enabled the measurement of gravity changes related to the 26 December 2004 SumatraAndaman (Indonesia) earthquake (Han et al. 2006).

Nevertheless, one of the main post-event application fields of remote sensing is surface deformation mapping whereas both optical and SAR data are utilized (Tronin 2010). Approaches based on optical data use methods and concepts of change detection based on pre- and post-event data (Saraf 2000) applying a sub-pixel correlation technique in order to be able to quantify horizontal movements with a high accuracy (Van Puymbroeck et al. 2000; Remi \& Avouac 2002; Dominguez et al. 2003; Avouac et al. 2006; Leprince et al. 2007; Ayoub et al. 2009).

Differential SAR interferometry (D-InSAR) is a widely established method for mapping significant surface deformation signatures associated with faults, fractures and subsidences (Massonnet et al. 1993; Massonnet 1995; Massonnet \& Feigl 1998) induced by earthquakes. E.g. Reale et al. (2011) show the potential of a SAR system to monitor post-seismic deformations with a high timely resolution in an operational way. As already mentioned, there are also pre-event or inter-event applications of this technique, but it is regarded as the best tool for studying earthquake deformations especially at the moment after the shock (Tronin 2010). Based on phase difference of multi-temporal radar observations acquired before and after a hazard event when deformation has occurred, ground deformation and displacements on the Earth's surface in range of centimetres and millimetres can be measured in a spatially continuous way (Tralli et al. 2005; Joyce et al. 2009a). Pre- and post-event SAR data was acquired and D-InSAR techniques were applied for example for the 17 January 1995 Kobe (Japan) (Ozawa et al. 1997), 9 July 1998 Azores (Catita et al. 2005), 26 December 2003 Bam (Iran) (Stramondo et al. 2005; Erten et al. 2010), 24 February 2004 Al Hoceima (Morocco) (Tahayt et al. 2009), 26 December 2004 Sumatra (Indonesia) (Chini et al. 2008), 14 November 2007 Tocopilla (Chile) (Motagh et al. 2010), 12 May 2008 Sichuan (China) (Chini et al. 2010; Liou et al. 2010; Zhang et al. 2010), or 12 January 2010 Port-au-Prince (Haiti) (Eineder et al. 2010) earthquakes to quantify co- and post-seismic deformations.

Since InSAR provides precise measurements with a distance of a few kilometres away from the actual fault but is limited in generating complete deformation information in the near fault zone, (Tronin 2010) states, that a combined use of optical and SAR data based displacement mapping techniques could be supplementary, whereas high resolution optical data can be used for post-event deformation mapping in the epicentre areas.

\subsection{Vulnerability Parameters}

Remote sensing for earthquake vulnerability assessment is a less long established research field than for earthquake hazards itself. While some examples explicitly exploit and evaluate the capabilities of remote sensing generally (e.g. Rathje \& Adams 2008; Taubenböck et al. 2008) or explicitly address certain vulnerability components (e.g. Chen 2002; Mueller et al. 2006), it can be stated, that this part of earthquake risk is only in the recent years subject to a more intense contemplation, especially from the remote sensing point of view. However, valuable efforts were made contributing to different vulnerability aspects of earthquake risk based on remote sensing concepts, data, and methods, which are presented in the following section. 


\subsubsection{Pre-Event}

Generally, remote sensing based mapping of land cover/land use, and components of the built environment such as buildings, infrastructures or lifelines on a wide geographical scope (Polli \& Dell'Acqua 2011) can be substantial and beneficial for risk assessment and management (Tralli et al. 2005).

The potentials of remote sensing contributing to create (earthquake) risk building inventories and subsequent assessment of their physical vulnerability are discussed in e.g. French \& Muthukumar (2006), Mueller et al. (2006), Ehrlich \& Zeug (2008), Taubenböck et al. (2009a). Vulnerability related building parameters that can be extracted from remote sensing data incorporate building footprint, height, shape characteristics, roof materials, location, period of construction, and structure type. Especially very high and high spatial resolution optical imagery is found to be suitable to quantify and characterize the building stock based on manual cartographic methods, statistical enumeration of samples (Ehrlich et al. 2010) or automatic image information extraction methods (Sahar et al. 2010; Borzi et al. 2011). Especially the latest generation of optical spaceborne sensors are perceived as a breakthrough for operational applications especially where no alternative data source is available such as in third world countries and smaller and medium size remote urban areas (Deichmann et al. 2011). Combining several optical sensors and LiDAR data allows the automated evaluation of seismic building vulnerability with a high accuracy (Borfecchia et al. 2010), whereas e.g. the combined use of optical and SAR data is used to derive crucial parameters such as building footprint and floor number (Polli \& Dell'Acqua 2011).

In order to contribute to the assessment of demographic vulnerability components such as the regionalized number of population, spatial disaggregation approaches of population census data based on remotely sensed data are proposed (Dobson et al. 2000; Chen 2002). Aubrecht et al. (2012) provide an overview on available multi-level geospatial information and modelling approaches from global to local scales that could serve as inventory for people involved in disaster related areas. In absence of or when only outdated information on total population is available, approaches for spatial extrapolation of punctual population data have been presented (Taubenböck et al. 2007).

Based on proxy variables derived from very high resolution optical and LiDAR data Ebert et al. (2009) assess social vulnerability for an urban environment. Based on comparable data sets, Taubenböck (2011) uses physical proxies of the urban environment in order to build correlations of urban structure types (e.g. slums) with socio-economic parameters, such as income of the people, to spatially assess social vulnerability parameters, in this case financial capacity to recover. Zeng et al. (2012) use medium resolution optical imagery for modelling social vulnerability. More specifically, Prasad et al. (2009) address social vulnerability by using very high optical data for the identification of socioeconomic clusters within the built environment in order to subsequently assess seismic risk.

\subsubsection{Post-Event}

Post-event applications that utilize remote sensing data and techniques deal mainly with the identification of land cover / land use change induced by an earthquake (Chang \& Tang 2010). Analogous to pre-event studies, the focus of such applications is on the identification, description and assessment of the present and future conditions of the built and natural environment, and hence the elements exposed.

Since remote sensing is the only technology capable of immediately capturing the damage situation over a large affected area after a hazard event (Vu \& Ban 2010) it has become a valuable tool during emergency response (Dell'Acqua et al. 2009). Especially for post-disaster rapid damage detection, mapping and assessment, recovery, and rescue information in cases 
of a disaster event, remote sensing has proven its potential and can be identified as an operational tool to support decision makers with up-to-date spatial information (Joyce et al. 2009b; see also Saito \& Spence 2004; Voigt et al. 2007; van den Broek et al. 2009; Lang \& Tiede 2010).

However, especially rapid damage mapping is still primarily based on manual interpretation in order to avoid long (pre-)processing times (Trianni \& Gamba 2009) and to provide the acquired accuracy for rescue teams in events such as the 12 May 2008 Sichuan (China) (Wang et al. 2009b), 12 January 2010 Port-au-Prince (Haiti) (DLR-ZKI 2010), or 11 March 2011 Tōhoku (Japan) (ICSMD 2011a) earthquakes. Thereby, limitations due to misinterpretations and data availability are still a challenging task (Kerle 2010). Recognized damage is typically limited to severely damaged structures (Jaiswal et al. 2011), and patterns of damage are more likely to be accurately mapped whereas the quantification of damage intensity appears not feasible (Corbane et al. 2011).

Automated approaches are presented solely using post-event optical (Kaya et al. 2005; Vu et al. 2005) or SAR data (Balz \& Liao 2010), where the pre-event situation of buildings is e.g. simulated (ibid; Wang et al. 2009a). However, the use of change detection-based methods, which compare pre- and post-earthquake images are perceived to deliver more accurate and reliable results in general (Li et al. 2008; Ehrlich et al. 2009). This is due to the finding that damage assessment is principally a change detection problem, where the mapping classes are correlated with the level of damages experienced by the structures in the area of interest (Trianni \& Gamba 2009). Based on optical pre- and post- event space- and airborne imagery several concepts and methods are developed in order to detect change and subsequently derive earthquake damage of buildings in an automated way (Mitomi et al. 2002; Yano \& Yamazaki 2006; Adams et al. 2004; Kosugi et al. 2004; Turker \& San 2004; Turker \& Cetinkaya 2005; Kumar et al. 2006; Yamazaki \& Kouch 2006; Sertel et al. 2007; Yamazaki \& Matsuoka 2007; Teimouri et al. 2008; Turker \& Sumer 2008; Aydöner \& Maktav 2009; Aldrighi \& Dell'Acqua 2009; Li et al. 2010; Vu \& Ban 2010), also incorporating pre- and post-event LiDAR data in order to reach a high level of morphologic detail and accuracy (Vu et al. 2004; Li et al. 2008).

As data acquisition of optical imagery shortly after an earthquake may be limited due to cloud coverage and weather conditions and flight campaigns in remote areas can often not be carried out quickly, approaches are developed to assess earthquake damage to build structures by using pre- and post-event SAR data (Hoffmann 2007; Gamba et al. 2007; Matsuoka \& Yamazaki 2010; Schmitt et al. 2010) or combine pre-event optical and post-event SAR imagery (Stramondo et al. 2006; Chini et al. 2009; Brunner et al. 2010).

Also other elements of the built environment are under investigation such as critical infrastructures like transportation networks (Huang et al. 2009; Wang et al. 2011) and remote sensing based monitoring of reconstruction activities have been reported (Guo et al. 2010).

Recent applications also deal with the assessment of ecological aspects of vulnerability of a system such as investigations of the impact of the 2008 Wenchuan (China) earthquake on wildlife habitats using optical remote sensing data (Xu et al. 2009; Deng et al. 2010) and DEM data (Yu et al. 2011) or quantify damage to vegetation based on pre-and post-event optical data (Ge et al. 2009).

\section{Trends, research projects and initiatives}

\subsection{Trends - What was in the centre of research?}

Numerous devastating natural disasters in the 1980ies triggered the United Nations to proclaim the International Decade for Natural Disaster Reduction (IDNDR). Against this 
institutional background, the Tokyo Declaration of 1989 was followed by the forming of a UN Special Committee and the establishment of national secretaries and committees (Verstappen 1995).

In order to give a comprehensive picture on general developments, technological innovations and 'hot' research topics on remote sensing capabilities in the earthquake risk context since the proclaimed time period, a quantitative analysis and categorization of the literature is performed. This analysis is both meant to complement the previous review and serve as a profound basis for the subsequent discussion about future research activities in the next chapter.

\subsubsection{Search Criteria and Sampling Methodology}

Based on the assumption that researchers tend to publish in well-established journals (Caron et al. 2008), peer-reviewed journals listed in the Thomson Reuther's ISI Web of Knowledge are screened from 1991 to July 2011. This is believed to give a significant overview of main developments and trends without aiming for completeness though.

First, title, keywords, and abstract of all papers listed are screened for a mandatory combination of the buzzwords "remote sensing" and "risk", "earthquake", "hazard", "vulnerability", and the search terms' lingual variations such as plural, adjective etc., respectively. This implies that remote sensing is regarded as a central methodological element in the respective paper which is worth being already pointed out or at least mentioned in the title, keywords or abstract and not only in the full text. This might be especially true for papers published in journals related to research disciplines with a focus not strictly bound to remote sensing (such as this journal). In contrast, for papers published in remote sensing journals there might be less emphasis of the central methodological element necessary, since a relation to remote sensing is normally a prerequisite to publish in such a journal. Therefore, all 23 journals listed in the Thomson Reuther's subject category "remote sensing" are screened separately for the search terms without combing them with the buzzword "remote sensing".

The search results in a large error of commission, but what is found to be necessary in order to keep the error of omission as low as possible. By manual inspection of the respective search results, papers are identified that have a direct relation to earthquakes and its components such as the analysis and applications already presented above. For reasons of consistency, e.g. secondary threats that are tackled by remote sensing are not integrated. One may think of numerous papers that meet these search criteria like investigations of earthquake triggered landslides by means of remote sensing or tsunami damage observed from remote sensing data. Also papers that are identified based on very general search combinations, e.g. "remote sensing" and "risk", such as investigations of droughts or malaria risks integrating remote sensing are naturally not further considered.

\subsubsection{Categorization of the literature}

Based on the sampling scheme and exclusion criteria, 251 papers were identified for the period from 1991 to end of July 2011. Following the presented categorization of the literature, the papers are indexed in dependency if the focus is on hazard or vulnerability components for pre- or post-event applications. Additionally, a categorization of the papers corresponding to the geometric resolution of the respective sensors deployed has been made.

There is a considerable trade-off between the geometric resolution of remote sensing data and the aerial coverage of a scene or data set (Rathje \& Adams 2008). Generally, remote sensing data with a coarse geometric resolution provide large spatial coverage (in terms of scene size), 
what implies that fewer data sets are needed to evaluate a large area. In contrast, a high geometric resolution implies relatively small spatial coverage (in terms of scene size) (ibid.). In table 1 several remote sensing systems deployed in earthquake research are listed with affiliated geometric resolution, swath, and revisit capability. The categorization according to the geometric resolution of the sensors is adapted from the scheme presented by Neer (1999) (revealed in Möller 2011) for optical sensors. Being aware that e.g. SAR data do not contain the same thematic information as optical data with the same geometric resolution, the categorization is later on adapted also for non-optical sensors for terms of consistency.

Based on the quantitative sensor characteristics, a qualitative categorization of the sensors is made. Table 1 shows the assumed spatial scales the respective analyses are typically applied on. These reach from "focal" to "local" to "regional" to "national". Generally, it can be assumed that data with a coarser geometric resolution and larger spatial coverage per scene are able to contribute to overall evaluation of pre- and post-events studies, whereas it is yet both difficult and expensive to obtain high geometric resolution data over the entire area threatened or affected by an earthquake (Rathje \& Adams 2008). Clearly, the geometric resolution of the sensors, affiliated scene sizes and the spatial scales the analyses are typically applied on have also to be set in context of the objects to be analysed. There may be applications where no substantial added value may arise answering the respective research questions based on data with a higher geometric resolution. For instance, the use of coarse resolution remote sensing data in order to analyse large-scale phenomena and objects such as large active faults may deliver appropriate results, whereas an earthquake-related evaluation of small-scale objects such as buildings may, by trend, represent only a rough estimation based on such data. However, the categorization also aims to identify characteristic spatial scales for respective application fields. In addition it should be noted that some of the sensors shown in table 1 in the category "national" can be considered more as sensors allowing "continental" or even "global" analysis, but are integrated in this category for terms of lucidity. 
Table 1 Overview of several remote sensing systems deployed in earthquake research

\begin{tabular}{|c|c|c|c|c|c|c|}
\hline Platform/Satellite & Sensor/Mode & $\begin{array}{l}\text { Geometric } \\
\text { resolution } \\
\text { (Nadir) }[\mathrm{m}]\end{array}$ & Swath $[\mathrm{km}]$ & Revisit capability & $\begin{array}{l}\text { Categorization of } \\
\text { geometric resolution } \\
\text { according to } \\
\text { Neer (1999) }\end{array}$ & $\begin{array}{l}\text { Spatial scales } \\
\text { analysis } \\
\text { are typically applied } \\
\text { on according to } \\
\text { swath/scene size }\end{array}$ \\
\hline Airborne & LiDAR & $0.5-1$ & $\begin{array}{l}\text { daily coverage of } \\
1-100 \mathrm{~km}^{2}\end{array}$ & Mobilized to order & \multirow{11}{*}{$\begin{array}{l}\text { very high and } \\
\text { high resolution }\end{array}$} & \multirow{11}{*}{ focal } \\
\hline \multirow[t]{2}{*}{ Worldview } & Panchromatic & 0.46 & 164 & 11 davs & & \\
\hline & Multispectral & 1.85 & 10.4 & 1.1 days & & \\
\hline \multirow[t]{2}{*}{ Quickbird } & Panchromatic & 0.6 & \multirow{2}{*}{16.5} & \multirow{2}{*}{ 1.5-3 days } & & \\
\hline & Multispectral & 2.4 & & & & \\
\hline \multirow[t]{2}{*}{ Ikonos } & Panchromatic & 1 & \multirow{2}{*}{11} & \multirow{2}{*}{$1.5-3$ days } & & \\
\hline & Multispectral & 4 & & & & \\
\hline Cosmo-Skymed $^{\wedge}$ & Spotlight & $<1$ & 10 & $\sim 37$ hours & & \\
\hline \multirow[t]{2}{*}{ TerraSAR-X } & Spotlight & 1 & 10 & \multirow{2}{*}{$\begin{array}{l}11 \text { day repreat cycle; } \\
2.5 \text { day revisit capability }\end{array}$} & & \\
\hline & Stripmap & 3 & 30 & & & \\
\hline Radarsat-2 & Ultra-fine & 3 & 20 & Every few days & & \\
\hline \multirow[t]{2}{*}{ SPOT-5 } & Panchromatic & 5 & $60-80$ & \multirow{2}{*}{11 times every 26 days } & \multirow{6}{*}{$\begin{array}{l}\text { medium } \\
\text { resolution }\end{array}$} & \multirow{6}{*}{ local } \\
\hline & Multispectral & 10 & $60-80$ & & & \\
\hline Rapid Eye & Multispectral & 6.5 & $77 \times 1500$ & 1 day & & \\
\hline \multirow[t]{2}{*}{ ALOS } & AVNIR & 10 & 70 & \multirow{2}{*}{$\begin{array}{l}\text { Several times per year } \\
\text { as per JAXA acquisition } \\
\text { plan }\end{array}$} & & \\
\hline & PALSAR (Fine) & 10 & $40-70$ & & & \\
\hline Radarsat- $1 /-2$ & Fine & 8 & 50 & Every few days & & \\
\hline Landsat- 5 & TM Multispectral & 30 & & & \multirow{8}{*}{$\begin{array}{l}\text { coarse } \\
\text { resolution }\end{array}$} & \multirow{8}{*}{ regional } \\
\hline \multirow[t]{2}{*}{ Lansat-7* } & ETM+ Panchromatic & 15 & 185 & Every 16 days & & \\
\hline & ETM+ Multispectral & 30 & & & & \\
\hline TerraSAR-X & ScanSAR & 18 & 100 & $\begin{array}{l}11 \text { day repreat cycle; } \\
2.5 \text { day revisit capability }\end{array}$ & & \\
\hline \multirow[t]{2}{*}{ Radarsat-1/-2 } & Standard & 25 & 100 & \multirow{2}{*}{ Every few days } & & \\
\hline & Wide & 30 & 150 & & & \\
\hline ERS-2 & & 30 & 100 & 35-day repeat cycle & & \\
\hline Envisat & ASAR standard & 30 & 100 & 36-day repeat cycle & & \\
\hline ALOS & PALSAR (ScanSAR) & 100 & $250-350$ & $\begin{array}{l}\text { Several times per year } \\
\text { as per JAXA acquisition } \\
\text { plan }\end{array}$ & \multirow{5}{*}{$\begin{array}{l}\text { very coarse } \\
\text { resolution }\end{array}$} & \multirow{5}{*}{ national } \\
\hline Radarsat-1/-2 & ScanSAR wide & 100 & 500 & Every few days & & \\
\hline Terra /Acqua & MODIS & $250,500,1000$ & 2300 & $\begin{array}{l}\text { At least twice daily for } \\
\text { each satellite }\end{array}$ & & \\
\hline NOAA & AVHRR & 1100 & 2399 & Several times per day & & \\
\hline Envisat & ASAR ScanSAR & 1000 & 405 & 36-day repeat cycle & & \\
\hline
\end{tabular}

Source: Sensor/Mode characteristics "Geometric resolution (Nadir) [m]", "Swath [km]", and "Revisit capability" according to Joyce et al. (2009). Characteristics for "Airborne LiDAR" are taken from Rathje and Adams (2008).

\subsubsection{Results}

In Figure 2 the 251 identified peer-reviewed journal articles are visualized according to their assignment in terms of risk components, spatial scale and year of publication. As described, the papers are subdivided in dependence if the research is hazard or vulnerability related and further differentiated in pre- and post-event research. The spatial scales are to be understood according to the sensor categories in table 1. For multisensoral approaches the category of the sensor with the highest resolution deployed is used. The temporal differentiation corresponds to the publication year of the respective paper. Note that the quantitative axis is logarithmically scaled. Furthermore the absolute number of papers is visualized in a cumulative manner over the time. 


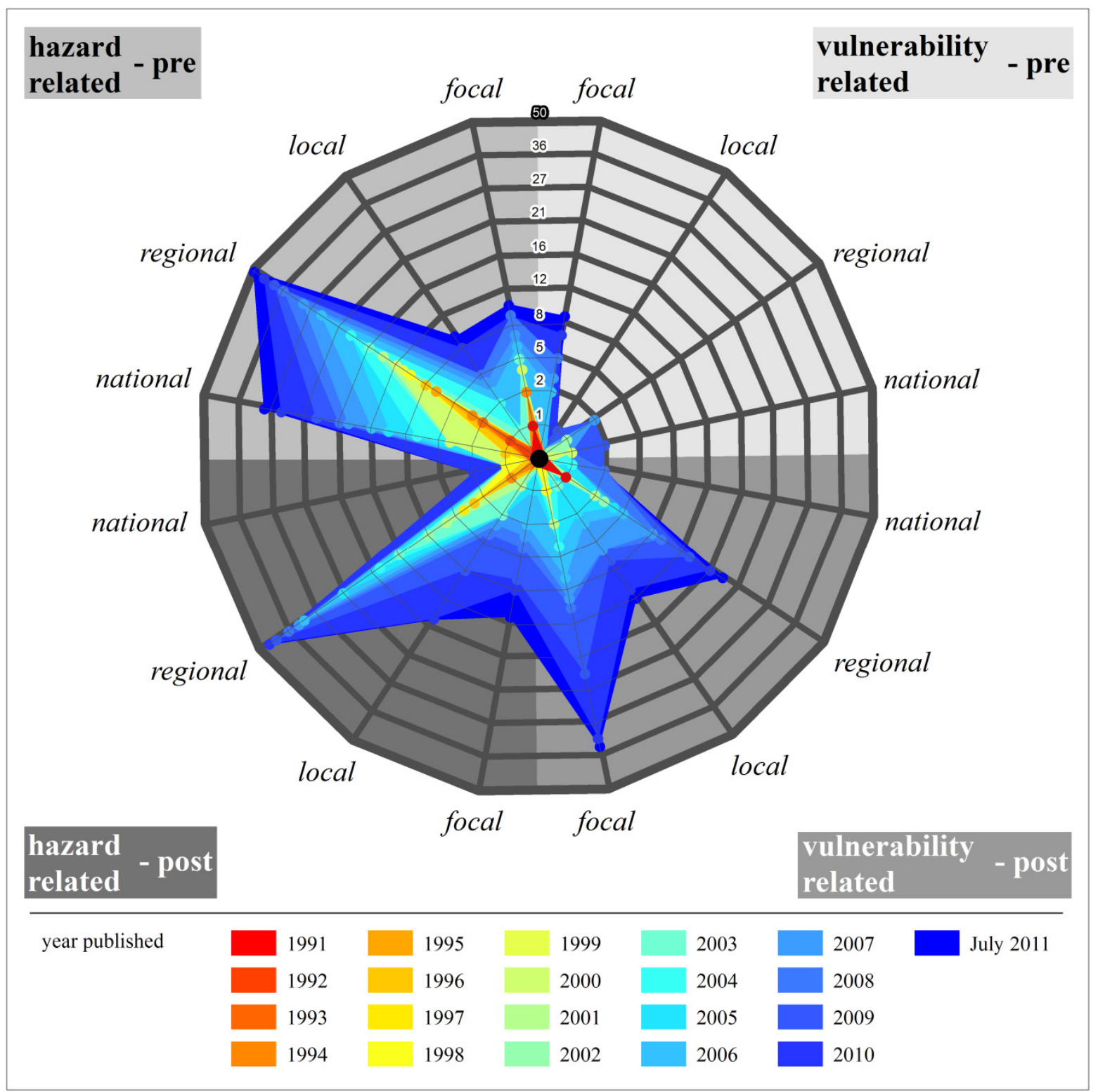

Figure 2 Visualization of the number of peer-reviewed journal articles differentiated according to risk components, spatial scales and year of publication based on a logarithmic scaled axis.

First, the quantitative characteristics of the overall categories are noticeable. Continuous research was published with contributions to assess earthquake hazards and its components both for pre- and post-event analyses and applications (hazard related pre-event: 97 papers; hazard related post-event: 76 papers). Especially since the mid of the last decade post-event damage analysis have increased (damage related post-event: 64 papers), whereas the number of papers dealing with pre-event vulnerability components is still comparatively low (vulnerability related pre-event: 14 papers).

In detail, pre-event hazard analysis on a (supra-) national scale dealt mainly with the quantification of possible earthquake precursors such as thermal anomalies of the earth surface and atmosphere. In contrast, regional, local, and focal analysis focussed primarily on an identification, description and measurement of geomorphometric features and seismotectonic parameters such as detection of faulting. Especially analyses and applications that can be associated to the post-hazard category are based on the development of change 
detection techniques such as D-InSAR for SAR based or sub-pixel correlation techniques for optical data in order to quantify earthquake induced surface deformations. Being less long in the interests of research, analysis and applications contributing to the post-event impact related part of earthquakes mainly contributed to assess structural damage of the built environment. The advent of high and very high resolution optical, SAR and LiDAR sensors enabled the quantification of earthquake damage with viable accuracies, whereas studies on a regional level offer quick overview assessments. Less found, but increasing since the last years, are concepts, analysis and applications focusing on the pre-event vulnerability part of earthquake risk that mainly deal with the detection and assessment of elements at risk such as buildings and their physical vulnerability using latest generation air and spaceborne remote sensing sensors. In this context, remote sensing can be regarded as a widely deployed source of data and established methodological element for hazard centred studies, which was already used since the availability of satellite images (Tronin 2006), whereas especially for pre-event vulnerability related research remote sensing can still be considered as relatively new source of information (Nassel \& Voigt 2006). We may conclude that this development is triggered both by the changing focus of the scientific community that the assessment of vulnerability and its constituent elements is an important part of a comprehensive risk analysis and at the same time by the availability of sensors that first enabled an appreciable share of remote sensing capabilities to these components of earthquake risk.

Finally it should be mentioned that, beside the discussed developments and trends concerning the specific earthquake risk categories, an overall increase of peer-review literature can be found. This increase follows a general increase of peer-reviewed publications related to remote sensing, naturally connected to the impressive pace of technical innovations in this scientific field (Blaschke 2010). Additionally, the increase is also triggered by the scientific community perceiving remote sensing as a valuable tool in earthquake risk related investigations. This finding is e.g. quantitatively manifested in documented research such as two special issues in remote sensing journals which deal with the detailed analysis of the Wenchuan (China) earthquake on the basis of concepts, data, and methods of remote sensing (Satellite observations of the Wenchuan Earthquake, 12 May 2008, International Journal of Remote Sensing Volume 31, Issue 13 (Singh 2010); Special Section on Remote Sensing of the Wenchuan Earthquake, Journal of Applied Remote Sensing, Volume 3 (Guo 2009)).

\subsection{Current research projects and initiatives}

With the designation of the 1990s as the International Decade for Natural Disaster Reduction (IDNDR) the United Nations General Assembly recognized the importance of reducing the impact of natural disasters. Since then, many different initiatives have been started to strengthen international science and stakeholders to benefit to risk reduction capabilities:

- On the one hand, political initiatives and programmes are especially focusing on the use of earth observation data to tackle the multi-faceted problem of earthquake risk management. The intergovernmental Group on Earth Observation (GEO) is coordinating international efforts to build a Global Earth Observation System of Systems (GEOSS). This initiative was launched in response to calls for action by the 2002 World Summit on Sustainable Development, aiming at exploiting the growing potential of remotely sensed data to support decision-making. With the topic "disasters" as one of nine "societal benefit areas" (SBA) within GEO, the political significance of this topic becomes obvious (GEO 2011).

The Committee on Earth Observation Satellites (CEOS), as a space component of GEOSS, coordinates civil space-borne missions to prevent unnecessary overlap. Since 2008 a CEOS Disaster SBA team coordinates all actions with respect to disaster management (CEOS 2012). 
- The Global Monitoring for Environment and Security (GMES) is a joint initiative of the European Commission and European Space Agency (ESA), which aims at achieving an autonomous and operational Earth observation capacity and is the European Union's contribution to GEOSS. Pre-operational implementation of disaster related mapping services have been demonstrated in multi-disciplinary pre-cursor projects within the European Commission Framework Programme such as SAFER (FP7; SAFER 2011), and PreView (FP6 PreView 2012) aiming at real-time emergency response services, or GMOSAIC (FP7 G-MOSAIC 2012) aiming to support early warning and crisis management operations. With GMES Initial Operation (GIO) Emergency Management Support (GIOEMS) the goal is establishment of the operational service for post- and preparation phases (GIO 2012). Within these frameworks remote sensing plays a critical role as actual source of information for multiple hazards in rapid mapping and response applications.

- Furthermore, the United Nations Office for Outer Space Affairs for instance is promoting international cooperation in the peaceful uses of outer space (UNOOSA 2011). Within, a 24-hour hotline is operating as the United Nations focal point for satellite imagery requests during disasters and manages the United Nations Platform for Space-based Information for Disaster Management and Emergency Response (UN SPIDER 2011), whereas the United Nations Office for the Coordination of Humanitarian Affairs (UNOCHA 2012) acts as an operational coordinator in crisis situations. In 2000 the European, French and Canadian Space Agencies initiated the "International Charter Space and Major Disasters" (ICSMD 2011b). The Charta represents an institutionalized cooperation between commercial remote sensing systems operators (Digital Globe, GeoEye, Spotimage, etc.), and (inter)national operators (JAXA, USGS, ESA, etc.). The goal is to provide rescue teams and local stakeholders with actual (geo-)information immediately after an hazardous event. Thereby, the Charter is responsible for the initial satellite image acquisition and processing/mapping/analysing facilities such as UNOSAT (UNOSAT 2011), DLR-ZKI (Voigt et al. 2007), SERVIR (SERVIR 2012), SERTIT (SERTIT 2012), or e-GEOS (eGEOS 2012) transform remotely sensed data in actual information for emergency response. The derived information such as damage maps is subsequently used by humanitarian relief organisations such as "Medicins Sans Frontières", "German technical relief agency" or "Red Cross" in order to direct supporting measures.

- Another major initiative from the private sector is the Global Earthquake Model (GEM) financed mainly by re-insurance companies - bringing together state-of-the-art science, regional, national, and international organisations as well as individuals, in a global collaborative effort that aims at a lasting impact on seismic risk assessment (GEM 2011). Remote sensing is among manifold disciplines - e.g. civil engineering, seismology, architecture or social sciences - a crucial part to provide spatial, quantitative information for, amongst others, an intended global exposure and consequences databases. Remote sensing data and methods are developed for data inventory capturing, for interdisciplinary combination with in-situ field measurements, gathering of existing earthquake databases, crowd sourcing, vulnerability estimation methods, etc. The initiative clearly reveals the community's efforts for multi-, inter- and transdisciplinary progress in earthquake risk assessment. Within the context of regional programmes such as the Earthquake Model Central Asia (EMCA 2011), or the Earthquake Model of the Middle East Region (EMME 2011), remote sensing is also used both for the assessment of seismic hazard and vulnerability.

- On the other hand, manifold initiatives have been set up to coordinate and proclaim integrated, multi- and transdisciplinary programs for risk reduction. Amongst others the International Council for Science (ICSU) proposed in 2006 that despite all the existing or already planned activities on natural hazards, an integrated research programme on disaster risk reduction, integrated across the hazards, disciplines and 
geographical regions, is an imperative (ICSU 2011). Within the United Nations, the 'International Strategy for Disaster Reduction' (ISDR) is coordinating disaster risk reduction and ensuring synergies between the manifold players (UN/ISDR 2011). For instance, the International Disaster and Risk Conference (IDRC) is complementing UN-ISDR's governmental policy and strategy-oriented focus by concentrating on providing a network for experts, practitioners and institutions from science, technology, business, and civil society (IDRC 2011). Further initiatives are e.g. the Global Facility for Disaster Reduction and Recovery managed by the World Bank (GFDRR 2011), which funds e.g. GIS-based platforms for risk analysis such as CAPRA (GFDRR 2012). Therein remote sensing represents a critical source of data. Another example is the integrated Disaster Risk Management program managed by the Asian Development Bank (ADB 2011).

- The Understanding Risk Network (UR, 2012) is an example initiative connecting a global community of experts and practitioners to provide a permanent online space where the community can share ideas and collaborate. Furthermore, conferences are held every two years. On a more stakeholder related level, NGOs are found to have the potential to play a significant role in natural disaster mitigation and preparedness (Benson et al. 2001), since they can operate on grassroots level with communities, enjoy comparatively high operational flexibility, and work often with the most marginalized groups in society (UN/ISDR 2006).

\section{Proposing research directions based on the status quo: Towards a roadmap for remote sensing}

This literature review of remote sensing data, methods, applications and products shows a huge methodological and thematic spectrum and proves high relevance to the risk community: The capability to provide consistent, up-to-date, independent and large-area spatial data for basically any location around the globe to support and analyse hazard and vulnerability related questions at different spatial scales is beyond controversy. However, the qualitative and quantitative review also identifies key gaps in research and demonstrates differences between theoretical capabilities of remote sensing and the status quo. Based on this review, as well as on interviews with experts, experiences in related projects, advisory boards and at conferences we propose research directions for remote sensing in order to increase the notion on earthquake risk and the field's impact and relevance for the different groups involved.

It is obvious that the issue of earthquake risk assessment and emergency management is of multidimensional complexity with different groups such as politicians, stakeholders, (insurance) industry, different disciplines within science (e.g. seismology, geophysics, civil engineering, remote sensing, social sciences) as well as people themselves having different perspectives, different unsolved questions, and different open issues. In this manner, we aim to derive, discuss, and suggest a path for future research directions and initiatives according to these different points of view.

\subsection{Recommendations for future scientific research}

In general, future scientific research needs to incorporate the documentation and understanding of earthquake hazards and related measurable effects as well as the characterization and assessment of the vulnerability of the elements exposed within a clearly accepted conceptual risk framework.

However, the manifold conceptual frameworks reviewed regarding risk and its components lack common taxonomy and nomenclature. We argue for a demystification of terminology 
and acceptance of new conceptual approaches only if significant value-adding is achieved. This is crucial in order to overcome conceptual barriers by setting aside often emphasised differences, which are found to be less conceptual but rather terminological (Wolf 2011). Since a fragmented understanding of epistemological frameworks is at danger to miss out innovative ideas and bundling strengths (Hufschmidt 2011), the development of a common, framing taxonomy and ontology in the context of risk research has to be attained - as already postulated by e.g. Brooks (2003) or Janssen \& Ostrom (2006).

From a remote sensing perspective manifold case studies have been carried out; however examples evaluating the current maximum capabilities of remote sensing to assess earthquake risk in a systematic way are still absent. Thus, we propose integrative studies incorporating all remotely sensed data sets available to date - from LiDAR to SRTM, from SAR with different polarisations to panchromatic to multi-, super- and hyperspectral airborne and spaceborne data to ground-based remote sensing data with different geometric resolutions and repetition rates - to evaluate the capability and limitation of multi-source remote sensing for pre- and post-event hazard and vulnerability analysis at different spatial scales. When brought out for areas that are representative for earthquake-prone regions, such systematic evaluations would demonstrate the specific capabilities and effectiveness of individual data sources. Subsequently, the results can be the foundation in order to provide consistent and area-wide seismic risk assessment and monitoring in a standardised and operational way by developing automated thematic processors.

More specifically, as shown, remote sensing techniques allow for monitoring tectonic activities such as surface deformations from space. However, nowadays systematic and areawide monitoring is mostly restricted by data availability. For instance, Lundgren et al. (2004) show these capabilities of surface deformation monitoring, but for the limited area of a volcanic region. However, missions that are capable of monitoring tectonic activities and geotectonic threats from space with a high accuracy and high timely resolution are planned or in a conceptual phase. The proposed TanDEM-L mission (Moreira et al. 2011) aiming at a systematic, large-area interferometric monitoring will be a chance to better understand the Earth's dynamic surface processes and to improve prediction capabilities in the long term. For instance, correlations between displacements and strain build-up or relaxation may be improved (Eineder et al. 2009; Minet et al. 2008). More promptly, Salvi et al. (2012) emphasize that the Sentinel-1 (ESA 2011) data acquisition strategy allows effective coverage for interferomteric data over active seismically regions at global level by acquiring data in Interferometric Wide swath mode with $250 \mathrm{~km}$ swath and $5 \times 20 \mathrm{~m}$ of geometric resolution (in range and azimuth respectively) and a minimum revisit of 12 days with one satellite, and 6 days with both. These data are found to have the potential to substantially improve the scientific understanding and allow operational monitoring of the seismic cycle. By means of such data, a geodetic monitoring from space and thus quantification of changes regarding seismic hazards becomes viable.

Beyond this, Tronin (2006) states, that future earthquake hazard related applications may incorporate gas analysers with a high spatial resolution and sensitivity which can be helpful for earthquake prediction and warning.

Regarding vulnerability the above proposed high-end studies would allow for a systematic analysis of direct or indirect correlations between the phenomenon of vulnerability (e.g. building stability or time-dependent population distribution) and remotely sensed data. To accomplish such a proposition, systematic strategies and substantial data bases for validation including pre- and post-disaster information on e.g. building stocks, their seismic vulnerability and (eventually) experienced damage is needed. The latter may be the basis to develop consistent and robust damage scales for remote sensing estimates according to 
different data such as optical and SAR with various resolutions as proposed by Rathje \& Adams (2008).

However, also for the assessment of pre-event seismic building vulnerability, common scales are needed in order to link remote sensing observations to scales which are designed to work on a comparatively high level of aggregation such as the EMS-98 (Grünthal et al. 1998) as well as locally adapted building codes. In this manner, remote sensing is not to be regarded as a panacea in general, and can be further extended when e.g. combined with approaches such as automated ground based data collection (Wieland et al. 2012), crowdsourcing (Heipke 2010) or collective sensing (Blaschke et al. 2011).

Although many regions of the world are characterized by a lack of available data, one may think of refining for example existing aggregated geospatial information related to earthquake risk such as global building inventories (Jaiswal et al. 2010) or regional census data using remote sensing data for spatial disaggregation (Setiadi et al. 2010) and enhancement also. Vulnerability is less static but rather highly varying over space and time. Many earthquake prone regions of the world show a high dynamic in terms of e.g. settlement development. Thus, up-to-date assessment, monitoring and modelling of the expectable timely developments of the elements exposed and their conditions is an essential task.

We conclude the scientific recommendations with the observation that benchmarking of the manifold scientific contributions is largely absent. More research about research is mandatory to identify research gaps, promising solutions, dead ends or urgent needs for well-directed prioritization of future science (see also Taubenböck \& Geiß 2012 for a comment).

\subsection{Synthesis from the quantitative analysis of literature}

Overall, the quantitative analysis of literature on remote sensing for earthquake risk analysis clearly reveals an academic void for vulnerability studies in the pre-event phase. The lion's share of research studies on pre-event vulnerability have to deal with the constraint of smallarea coverage. From our point of view, highly detailed analysis on building level are essential to demonstrate the applicability of remote sensing generally, but the intrinsic advantage of the bird's eye view of remote sensing is large-area coverage. The availability, costs, data handling and processing requirements especially of high resolution data represent nowadays a clear limitation regarding an area-wide deployment (Rathje \& Adams 2008). Against this background it can be stated that still strong efforts have to be undertaken working towards an area-wide, detailed, and yet integrative derivation of earthquake risk parameters in an operational way

Thus, we propose further research that explicitly addresses settlement scales on a coarser morphological level such as structure types that can be detected, characterized and assessed properly and cost-effective (see also Wyss 2012) when using remotely sensed data with geometric resolution characteristics that enable at the same time large-area coverage..

Furthermore, future research has to be directed to vulnerability assessments beyond isolated, singular case studies. Thus, generic methodologies and frameworks are needed which allow for applicability (implying transferability) around the globe. However, adjustments due to local and cultural idiosyncrasies cannot be bypassed. As complexity and investment for vulnerability analysis on highest scale are significant, we propose to direct research to a coarser level of abstraction, but therefore allowing area-wide coverage in a standardised way and if favoured adjustment to highest spatial and thematic detail. This also goes along with the idea of the research initiative of GEM to provide data and methods - amongst other disciplines - to basically allow generating systematic and standardized results all across the world. In order to prioritize tasks and areas of interest, research has systematically to be directed to earthquake risk hot spots (Dilley et al. 2005) and subsequently hierarchically brought out on multiple spatial scales. 


\subsection{Future needs from a technical perspective}

From a technical perspective, the constantly increasing availability and accessibility of modern remote sensing technologies provides new opportunities for a wide range of applications. However, still today, one major constraint is data costs. These are often too high for large-area coverage, or if smaller areas are needed data costs often are beyond the willingness or capabilities of local authorities. While satellite data are relatively low priced, some applications need high repetition rates or three-dimensional analysis, where mostly airborne and thus cost-intensive remote sensing is required. Future spaceborne missions such as the Sentinel programme of the ESA (ESA 2011) intend to provide continuity and guarantee the availability of ERS, Envisat, and SPOT-like observations (Berger \& Aschbacher 2012) to service providers and users since the technical lifetime of other missions will come to an end and in particular make data available free of charge.

Amongst others, launched, planned or proposed missions such as TanDEM-X (global DEM data with a geometric resolution of $\sim 12 \mathrm{~m}$ and relative vertical accuracy of $\pm 2 \mathrm{~m}$; LópezDekker et al. 2011), ALOS-2 (L-band SAR system with a geometric resolution of 1-10m; JAXA 2011), the RADARSAT constellation (planed as a medium resolution C-band mission it also includes high resolution modes at 3 and $5 \mathrm{~m}$ which were primarily designed for disaster management; CSA 2012), DESDynI (L-band SAR with a geometric resolution of $\sim 10 \mathrm{~m}$ and a multiple beam LiDAR instrument with a geometric resolution of $\sim 25 \mathrm{~m}$ and $1 \mathrm{~m}$ vertical accuracy; DESDynI 2011), CARTOSAT-3 (multispectral sensor with a geometric resolution of $0.25 \mathrm{~m}$ panchromatic; Katti et al. 2007), ALOS-3 (optical sensor with a geometric resolution of $0.8 \mathrm{~m}$ panchromatic and the capability to take stereo images with a swath of 50km; Suzuki 2012), WorldView-3 (superspectral sensor with a geometric resolution of $0.31 \mathrm{~m}$ panchromatic; DigitalGlobe 2012) or EnMAP (hyperspectral sensor with a geometric resolution of $30 \mathrm{~m}$; Heldens et al. 2011) have the potential to play a key role in future earthquake research. Thereby, the tasking of satellites (constellations) becomes more important in order to be able to provide the right images at the right time with the appropriate geometric resolution (ESA II 2012).

Furthermore, technical developments such as unmanned aerial vehicles may become a viable option especially for post-event rapid damage mapping (Bendea et al. 2008; Suzuki et al. 2008).

At the same time, the foreseeable increase of data volume will induce new challenges in terms of data storage, handling, mining and processing techniques. Investment in processing is still comparatively high due to mostly not fully automation of information generation procedures. During processing, adjustments are often needed due to e.g. different atmospheric conditions, land cover types, different user's requirements or the algorithms are still in experimental status. Therefore robust methodologies are needed, as for example automated settlement detection approaches based on optical (Pesaresi \& Gerhardinger 2011; Pesaresi et al. 2011) or SAR (Esch et al. 2010; Gamba et al. 2011) data, which build the basis for implementing fully automated processing chains reaching from data acquisition to user-ready products. In order to address the computational requirements of especially time critical applications the use of approaches such as high performance computing models (Plaza \& Chang 2008) appears promising.

We observe that regarding quality indicators the remote sensing literature predominantly focuses on accuracy assessment of the resulting product. However, this is not enough without a throughout discussion on performance analysis of the approach deployed with indicators such as degree of automation, level of semantic information derived, timeliness of product generation, robustness due to changes in input images or input parameters or economic viability considerations. 
On the topic of risk assessment using remotely sensed data an unmanageable number of projects have been, are, or will be running. In general, reporting and thus information sharing is a critical problem that can be tackled with the possibilities to disseminate geospatial data and results through e.g. online solutions such as GeoNode (GeoNode 2012). Also virtual globes such as Google Earth allow visualizing and sharing data, analysis and results in an easily accessible way.

Moreover, technological advancements in recent years have made it possible for Volunteer and Technical Communities (V\&TCs) such as OpenStreetMap (Ramm et al. 2010), Ushahidi (Ushahidi 2012), CrisisMappers (CrisisMappers 2012), Virtual Disaster Viewer (VDV 2012), Google Map Maker (Google 2012), InSTEDD (InSTEDD 2012) and others to provide increasing support to disaster risk management and emergency response efforts with spatial knowledge. OpenStreetMap even coordinates a Humanitarian OSM Team (HOSMT 2012). Thereby, the principle of open data sharing is of crucial mutual benefit for participating parties and especially for the remote sensing community in support of non-duplicative classifications, target-oriented product derivation, post-classification product enhancement or the availability of validation data.

However, regarding geodata, missing data documentation, standards such as proposed by the Open Geospatial Consortium (OGC 2012), compatibility or sharing of software is a not negligible problem. Generally, we experienced that municipalities/governments are working with different software environments and their individual definitions of describing the spatial domain. Feasible ways are possibly initiatives such as e.g. INSPIRE, which in that particular case aim at establishing an infrastructure for spatial information in Europe to support environmental policies on a community level, and policies or activities which may have an impact on the environment (INSPIRE 2012). To fully use and integrate the advantages of remote sensing products and enable comparisons, standards are required, on the data format, the land cover classes mapped, the spatial scales and units used, etc.

\subsection{The need for transdisciplinarity}

Especially the last paragraph includes the need for transdisciplinarity, since scientific results are valueless if they do not transform into practical value. In order to overcome the paradox of "knowing better and loosing even more" (White et al. 2001), the use of knowledge in hazard management has to be considered explicitly, whereby Fekete (2011) states that an assessment of the application of scientific results by the users should also be a critical part of research.

In this manner, projects such as LinkER (LinkER 2012) explicitly support the implementation of operational service products in emergency response.

In general, the authors experienced a knowledge gap between the stakeholder's and the remote sensing community. The knowledge gap includes e.g. data availability, data costs, data requirements or operational procedures, capabilities of products and thus, the development of applying remote sensing to earthquake hazard and vulnerability assessment as well as postevent capabilities. Comprehensive mapping of the user and stakeholder community, including consolidation of user demand, setting of precise pass/fail criteria on selected quality-ofservice parameters, and the specification of user requirements is necessary (ESA II 2012). Cartographic representation turns out to be an important aspect for the acceptance of the derived indicators. Examples are WebGIS, easily available data and applications with the capability to visualize and calculate results specific to the individual needs of particular stakeholders.

Another constraint is the difference between requirements and capabilities regarding accuracy of the respective products: the synoptic overview of remote sensing in the previous section shows area-wide and spatially highly detailed information extraction for various applications, but e.g. the accuracy of extracted pre-event vulnerability related information cannot compete with cadastral data sets. On the one hand accuracies of 80-90\% and sometimes even higher 
provide an objective basis for decisions and should increase credibility of EO based solutions. On the other hand these earth observation products are not established at the current legal foundation and now need to find juristic acceptance.

From a transdisciplinary perspective, the question arises to what extent the remote sensing community wants to engage for promotion of usage of its own data, results and products, or if this is to be seen as a political task. In any case, the promotion should be emphasized to e.g. major risk conferences such as the International Disaster and Risk Conference (IDRC) or major insurance industry conferences such as RIMS (RIMS 2012).

The engagement for promotion has already been pushed by an ESA workshop (ESA II 2012), which brought together the earth observation service industry, scientists and insurance and reinsurance companies. It was initiated in order to identify needs and common aims for the future usage of remotely sensed data. Key findings address inter alia the demand for a consistent and systematic provision of data and derived products for the extent of coverages required (most likely from national to global coverage). Beyond this, the establishment of new business models (e.g. based on a market survey) for EO data and products are demanded in order to reduce, respectively share the cumulative costs for large area coverage and provide standardized delivery mechanisms dealing with barriers related to licensing, since there is a clear message that says that industry budgets are limited for EO-based information. Preferred solutions when it comes to information distribution are platforms such as PERILS (PERILS 2012), which provide a single access point to data and information.

\subsection{The need for multidisciplinary}

The need for truly multidisciplinary research regarding natural hazards is often still little addressed (Fuchs et al. 2011). However, the integration of data, information, techniques, tools, perspectives, concepts and/or theories from two or more disciplines is not only promising to lead to new knowledge, but a must to tackle such multi-faceted problems of preand post-earthquake hazard and vulnerability analysis. As one example, the established service of earthquake loss estimates in near real-time allows specifying this need for multidisciplinary integration.

Real-time estimates of damage to buildings are based on calculating the acceleration of ground motion in settlements near a reported earthquake and depend critically on accurate knowledge of hypocentre and magnitude. However, the highest uncertainties for real-time assessments of casualties depend mostly on too little knowledge on the basic structures of the affected buildings (Wyss et al. 2006). The example of the indirect correlations between the phenomenon of building stability and remotely sensed data (see 5.1), requires systematic evidence of dependencies. This can only be achieved with sufficient databases on georeferenced buildings and their structural vulnerability.

The ways in which real-time loss estimates can be improved include the following. (1) Deepen the database on population and building stock (Wyss 2004) - a global requirement for social sciences, civil engineering, architecture, remote sensing, geography and beyond this, also governments. (2) Refine the earthquake source model used for strong motion calculations to allow extended sources of a length appropriate for the announced moment magnitude and (3) reduce the uncertainty in hypocentral depth estimates by a catalogue of regional most likely depths for the entire globe - requirements to geophysics, soil sciences and seismology. Finally, (4) educate local disaster managers on the benefits and limitations of international loss estimates in real time (ibid.) - requirements to capacity development and transdisciplinary communication. One may add that research on transferring damage assessment into economic losses is an obvious and necessary follow-up.

As it becomes more and more understood and accepted that single disciplines are decreasingly able to progress individually we would like to emphasize this paradigm shift and propose the willingness for an open dialogue about expectations, requirements, best practice guidelines 
(e.g. in form of white papers), capabilities and limitations beyond long-established communities. This could serve as a ground-breaking step to transfer remote sensing products into value-added products for the manifold players within the risk community.

\subsection{A political perspective}

Last but not least, from a political perspective, the societal loss of earthquakes is and will be enormous (see Introduction), e.g. expressed in financial loss the Haiti earthquake in 2010 was estimated to 7.8 billions US-dollars. Despite manifold scientific innovations the problem of earthquake prediction in a deterministic sense has not been solved yet (Zschau et al 2002).

Thus, continuous promotion and financing of integrated research and innovative technologies for prevention and early warning measures is crucial. As already mentioned above, an integrated research programme on disaster risk reduction, integrated across the hazards, disciplines and geographical regions, is an imperative (ICSU 2011). Coordination between manifold funding agencies, streamlining of procedures and frameworks setting priorities based on political directions, scientific advice and user requirements need to be established to ensure non-duplicative projects, well-directed progress and implementation phases. Initiatives with a voluntary nature such as e.g. GEO (GEO 2011) may serve as valuable institutionalized platforms in order to achieve the mentioned goals, but are nowadays confined due to their restricted financial resources and limited commitment of members.

A noble, but unrealistic goal would be the implementation of a general framework for a systematic global collection of all initiatives and projects, data, research results, information products, developed tools, participating stakeholders and a documentation of lessons learnt and best practice examples. A commendable example is demonstrated by the "Atlas of Vulnerability and Resilience Research", which collects all research studies, theses, reports and even minor studies that deal with vulnerability and resilience in context of disasters for Germany, Austria and Switzerland (Fekete \& Hufschmidt 2012).

Along this, an improvement of operational interfaces, a networking platform to increase user involvement, foster discussions and collaborations among the manifold stakeholders along the chain of risk management is essential. A commendable, initial example of this proposition is for instance the above mentioned Understanding Risk Network (UR 2012). However, an institutional responsibility for these tasks is unclear, not to mention knowledge about general responsibilities at global to local levels.

From a remote sensing perspective the ensuring of continuity of earth observation sensors and data availability and the subsequent derivation of precise, objective and reliable information is essential to promote sustainable development. As example, making use of remote sensing applications to track the temporal and spatial growth of urban areas as well as the changes of exposure of vulnerable elements is a crucial topic. Also, assisting institutions in rapid, precise, and objective assessments of impacts of earthquakes as a way to facilitate the delivery of humanitarian assistance to those communities affected by earthquakes is a necessary task.

However, the main challenge within the field of disaster reduction is to change people's perception so that they can recognize this notion of disasters as the outcome of a development process whereby societies have implicitly generated vulnerabilities and risks which become evident during the disaster (Villagrán de Léon 2006). With its fascinating images from above remote sensing is predestinated to reach the broad public. This can be the basis for raising awareness and creating consciousness of potentially affected people; this is a promising step for a major reduction of their personal vulnerability. The transparent communication of complex scientific results in an easy accessible environment and understandable language is of crucial importance, also when addressing stakeholders and politicians. However, it is clear that the step from scientific results to policy-making is challenging and often neglected, unfortunately from both sides. 
Moreover, this review of the manifold different aspects - scientifically, technically, trans- and multi-disciplinary and politically - without claiming to be complete, is meant as contribution towards an open dialogue among all involved parties for promoting remote sensing capabilities to support sustainable development.

Acknowledgments The authors thank Michael Eineder (DLR) for sharing his thoughts about future earthquake hazard related research and missions, Annette Fröhlich (DLR), Harald Mehl (DLR), EikeMarie Nolte (KIT) and Juan Carlos Villagrán de Léon (UNOOSA) for sharing their thoughts on the political perspective, Friedemann Wenzel (KIT) for hints regarding especially future scientific and technical issues, and Tobia Lakes (HU Berlin) for her comments on the initial manuscript. Furthermore, the authors want to acknowledge Beverly Adams (Guy Carpenter) for the fruitful discussions regarding the applicability of EO data and information related to the insurance industry. The authors also wish to thank the two anonymous reviewers for their constructive comments and suggestions. The research was founded partially by Helmholtz-EOS (Earth Observation System).

\section{References}

Adams JB, Huyck KC, Mansouri B, Eguchi TR, Shinozuka M (2004) Application of high-resolution optical satellite imagery for post-earthquake damage assessment: The 2003 Boumerdes (Algeria) and Bam (Iran) earthquakes. Research progress and accomplishments: 2003-2004, Multidisciplinary Center for Earthquake Engineering Research (MCEER), pp 173-186

ADB (2011) Asian Development Bank. Disaster risk management. Available online at http://www.adb.org/disaster/ Accessed 17 Oct 2011

Adger WN, Hughes TP, Folke C, Carpenter SR, Rockstroem J (2005) Social-ecological resilience to coastal disasters. Science 309:1036-1039

Adger WN, Kelly PM, Ninh HN (2001) Living with environmental change. Social vulnerability, adaption and resilience in Vietnam. Research Global Environmental Change. Routhledge, London

Adger WN (2006) Vulnerability. Global Environmental Change 16:268 - 281

Alcantara-Ayala I (2002) Geomorphology, natural hazards, vulnerability and prevention of natural disasters in developing countries. Geomorphology 47:107-124

Aldrighi M, Dell'Acqua F (2009) Mode-based method for matching of pre- and postevent remotely sensed images. IEEE Geosci Remote Sens Lett 6 (2):317-321

Alexander DE (2002) Principles of emergency planning and management. Terra Publishing, Harpenden

Alwang J, Siegel PB, Jorgensen SL (2001) Vulnerability: A view from different disciplines. Social protection discussion paper series No. 0115. Social Protection Unit, Human Development Network, The World Bank, Washington D.C.

Arellano-Baeza AA, Zverev AT, Malinnikov VA (2006) Study of changes in the lineament structure, caused by earthquakes in South America by applying the lineament analysis to the Aster (Terra) satellite data. In: Natural Hazards and Oceanographic Processes from Satellite Data, vol 37. Advances in Space Research. 37(4), 690-697.

Aubrecht C, Özceylan D, Steinnocher K, Freire S (2012) Multi-level geospatial modeling of human exposure patterns and vulnerability indicators. Taubenböck H, Post J, Strunz G (eds.) Remote Sensing contributing to mapping earthquake vulnerability and effects. Special Issue in Natural Hazards. To be published.

Avouac JP, Ayoub F, Leprince S, Konca O, Helmberger DV (2006) The 2005, Mw 7.6 Kashmir earthquake: Sub-pixel correlation of ASTER images and seismic waveforms analysis. Earth and Planetary Science Letters 249:514-528

Aydöner C, Maktav D (2009) The role of the integration of remote sensing and GIS in land use/land cover analysis after an earthquake. Int J Remote Sens 30 (7):1697-1717

Ayoub F, Leprince S, Avouac JP (2009) Co-registration and correlation of aerial photographs for ground deformation measurements. Isprs Journal of Photogrammetry and Remote Sensing 64:551-560

Balz T, Liao M (2010) Building-damage detection using post-seismic high-resolution SAR satellite data. Int J Remote Sens 31 (13):3369-3391

Bayuaji L, Sumantyo JTS, Kuze H (2010) ALOS PALSAR D-InSAR for land subsidence mapping in Jakarta, Indonesia. Canadian Journal of Remote Sensing 36:1-8

Begg JG, Mouslpoulou V (2007) Rangitaiki Plains: another veil is lifted: New lidar data from Bay of Plenty, New Zealand. Geological Society of New Zealand Miscellaneous Publications 123A, New Zealand 
Bendea H, Boccardo P, Dequal S, Giulio Tonolo F, Marenchino D, Piras M (2008) Low cost UAV for postdisaster assessment. Proceedings of The XXI Congress of the International Society for Photogrammetry and Remote Sensing, Beijing (China), 3-11 July 2008

Benson C, Twigg J, Myers M (2001) NGO Initiatives in Risk Reduction: An Overview. Disasters 25(3):199-215

Berger M, Aschbacher J (2012) Preface: The sentinel missions-new opportunities for science. Remote Sensing of Environment 120:1-2

Bilham R (2009) The seismic future of cities. Bulletin of earthquake engineering 7:839-887

Birkmann J (2006a) Indicators and criteria for measuring vulnerability: Theoretical bases and requirements. In: Birkmann J (ed) Measuring vulnerability to natural hazards. United Nations University Press, New York, pp 55-77

Birkmann J (2006b) Measuring vulnerability to promote disaster-resilient societies: Conceptual frameworks and definitions. In: Birkmann J (ed) Measuring vulnerability to natural hazards. United Nations University Press, New York, pp 9-54

Birkmann J (2007) Risk and vulnerability indicators at different scales: Applicability, usefulness and policy implications. Environmental Hazards 7 (1):20-31

Birkmann J, Krings S, Vollmer M, Wolfertz J, Welle T, Kühling W, Meisel K, Wurm M, Taubenböck H, Gähler M, Zwenzner H, Roth A, Voigt S, Dech S (2011) Indikatoren zur Abschätzung von Vulnerabilität und Bewältigungspotentialen am Beispiel von wasserbezogenen Naturgefahren in urbanen Räumen. Forschung im Bevölkerungsschutz, 13. Bonn

Blaikie P, Cannon T, Davis I, Wisner B (1994) At Risk: Natural hazards, peoples vulnerability and disasters. Routledge, London

Blaschke T (2010) Object based image analysis for remote sensing. ISPRS Journal of Photogrammetry and Remote Sensing 65:2 - 16

Blaschke T, Hay GJ, Weng Q, Resch B (2011) Collective Sensing: Integrating geospatial Technologies to understand urban systems - An overview. Remote Sensing 3 (8):1743-1776

Bogardi J, Birkmann J (2004) Vulnerability assessment: The first step towards sustainable risk reduction. In: Malzahn D, Plapp T (eds) Disaster and society - from hazard assessment to risk reduction. Logos Berlin, pp 72 - 82

Bogardi JJ, Villagrán De Léon JC, Birkmann J, Renaud F, Sakulski D, Chen X, Affeltranger B, Mensa A, Kaplan M (2005) Vulnerability in the context of climate change. Human Security and Climate Change, An International Workshop Holmen Fjord Hotel, Asker, near Oslo, 21-23 June 2005, p. 14

Bohle H-G (2001) Vulnerability and criticality perspectives from social geography. IHDP Update 2/2001, Newsletter of the International Human Dimensions Programme on Global Environmental Change, 2 :17

Bohle H-G, Downing TE, Watts MJ (1994) Climate change and social vulnerability. Towards a sociology and geography of food insecurity. Global Environmental Change 4 (1):37-48

Bollin C (2003) Community-based disaster risk approach. Experience gained in Central America. GTZ Deutsche Gesellschaft für technische Zusammenarbeit, Eschborn

Bommer JJ, Rodriguez CE (2002) Earthquake-induced landslides in Central America. Engineering Geology 63:189-220

Borfecchia F, Pollino M, De Cecco L, Lugari A, Martini S, La Porta L, Ristoratore E, Pascale C (2010) Active and passive remote sensing for supporting the evaluation of the urban seismic vulnerability. Italian Journal of Remote Sensing 42(3):129-141

Borzi B, Dell'Acqua F, Faravelli M, Gamba P, Lisini G, Onida M, Polli D (2011) Vulnerability study on a large industrial area using satellite remotely sensed images. Bulletin of Earthquake Engineering 9:675-690

Briuglio L (1995) Methodological and practical considerations for constructing socio-economic indicators to evaluate disaster risk. In: Programme on Information and Indicators for Risk Management. Institute of Environmental Studies, University of Columbia. IADB-ECLAC-IDEA, Manizalez, Colombia

Brooks N (2003) Vulnerability, risk and adaption: A conceptual framework. Tyndall Centre for Climate Change Research, working paper 38(16)

Brunner D, Lemoine G, Bruzzone L (2010) Earthquake damage assessment of buildings using VHR optical and SAR imagery. IEEE Transactions on Geoscience and remote sensing 48:2403-2420

Burby RJ (1991) Sharing environmental risks: How to control governments' losses in natural disasters. Westview Press, Boulder

Burton I, Kates RW, White GF (1993) The environment as hazard. 2 edn. Guildford Press, New York

Calvi GM (1999) A displacement-based approach for vulnerability evaluation of classes of buildings. Journal of Earthquake Engineering 3 (3):411-438

Calvi GM, Pinho R, Magenes G, Bommer JJ, Restrepo-Velez LF, Crowley H (2006) Development of seismic vulnerability assessment methodologies over the past 30 years. ISET Journal of Earthquake Technology 43 (3):75-104 
Cannon T (1993) A hazard need not a disaster make: vulnerability and the causes of 'natural' disasters. In: Merriman PA, Browitt CWA (eds) Natural disasters: Protecting vulnerable communities. Thomas Telford, London, pp 92-105

Cannon T (1994) Vulnerability analysis and the explanation of "natural disasters". In: Varley A (ed) Disasters, development and environment. John Wiley and Sons, Chichester, New York, Brisbane, Toronto, Singapore, pp 13-29

Cannon T, Twigg J, Rowell J (2003) Social vulnerability. Sustainable livelihoods and disasters. Report to DFID Conflict and Humanitarian Assistance Department (CHAD) and Sustainable Livelihood Support

Cardona OD (1999) Environmental management and disaster prevention: Two related topics - A holistic risk assessment and management approach. In: Ingleton J (ed) Natural disaster management. Tudor Rose, IDNDR, London, UK

Cardona OD, Hurtado JE (2000) Holistic seismic risk estimation of a metropolitan center. In: Proceedings of 12th World Conference of Earthquake Engineering, Auckland, New Zealand

Cardona OD (2004) The need for rethinking the concepts of vulnerability and risk from a holistic perspective: A necessary review and criticism for effective risk management. In: Bankoff G, Frerks G, Hilhorst D (eds) Mapping Vulnerability. Disasters, Development \& People. Earthscan, London, pp 37 - 51

Caron C, Roche S, Goyer D, Jaton A (2008) GIScience journals ranking and evaluation : An international delphi study. Transactions in GIS 12 (3):293-321

Carreno M-L, Cardona OD, Barbat AH (2007) Urban Seismic Risk Evaluation: A Holistic Approach. Natural Hazards 40:137-172

Carreno M-L, Cardona OD, Marulanda M-C, Barbat AH (2009) Holistic urban seismic risk evaluation of megacities: Application and robustness. In: Mendez-Victor LA, Oliveira CS, Azevedo J, Ribeiro A (eds) The 1755 Lisbon Earthquake: revisited. Springer, pp 167-183

Carreno M-L, Cardona OD, Suarez DC, Barbat AH Holistic Evaluation of risk in the framework of the urban sustainability. In: II Congreso Internacional de Medida y Modelización de la Sostenibilidad (ICSMM 09), Barcelona, Spain, 2009.

Cartwright S (2005) National civil defence emergency management plan order 2005. Published under the authority of the New Zealand Government, Wellington, New Zealand

Catita C, Feigl KL, Catalao J, Miranda JM, Victor LM (2005) InSAR time series analysis of the 9 July 1998 Azores earthquake. Int J Remote Sens 26 (13):2715-272

CEOS 2012 Committee on Earth Observation Satellites. Available online at http://www.ceos.org/images/PDFs/CEOS08Brochure.pdf Accessed 12 Jul 2012

Chang L, Tang Z (2010) Using remote sensing technology to assess land - use changes after the Northridge Earthquake. Disaster Advances 3:5-10

Chapman D (2001) Natural hazards, vol 2. University Press, Oxford

Chen K (2002) An approach to linking remotely sensed data and areal census data. International Journal of Remote Sensing 23:37-48

Chen SY, Liu PX, Liu LQ, Ma J, Chen GQ, Hu XY (2011) Comparative analysis between land surface temperatures obtained by field measurement and satellite remote sensing and its implication in earthquake research. Chinese Journal of Geophysics-Chinese Edition 54:747-755

Chini M, Atzori S, Trasatti E, Bignami C, Kyriakopoulos C, Tolomei C, Stramondo S (2010) The May 12, 2008, (Mw 7.9) Sichuan Earthquake (China): Multiframe ALOS-PALSAR DInSAR analysis of coseismic deformation. IEEE Geosci Remote Sens Lett 7 (2):266-270

Chini M, Bignami C, Stramondo S, Pierdicca N (2008) Uplift and subsidence due to the 26 December 2004 Indonesian earthquake detected by SAR data. Int J Remote Sens 29:3891-3910

Chini M, Pierdicca N, Emery WJ (2009) Exploiting SAR and VHR Optical Images to Quantify Damage Caused by the 2003 Bam Earthquake. IEEE Transactions on geoscience and remote sensing 47 (1):145-152

Chiroiu L, Adams B, Saito K (2006) Advanced techniques in modeling, response and recovery. In: Oliveira CS, Roca A, Goula X (eds) Assessing and managing earthquake risk. Springer, Dordrecht, The Netherlands, pp 427-448

Choudhury S, Dasgupta S, Saraf AK, Panda S (2006) Remote sensing observations of pre-earthquake thermal anomalies in Iran. Int J Remote Sens 27:4381-4396

Coburn AW, Spence RJS (1992) Earthquake protection. John Wiley \& Sons Ltd, Chichester, UK

Coburn AW, Spence RJS, Pomonis A (1994) Training Manual: Vulnerability and Risk assessment. 2 edn. UNDP Disaster Management Training Programme, Cambridge Architectural Research Limited, The Oast House, Malting Lane, Cambridge, UK

Corbane C, Carrion D, Lemoine G, Broglia M (2011) Comparison of Damage Assessment Maps Derived from Very High Spatial Resolution Satellite and Aerial Imagery Produced for the Haiti 2010 Earthquake. Earthquake Spectra 27:199-218

Cornell AC (1968) Engineering Seismic Risk Analysis. Bulletin of the Seismological Society of America 58 (5):1583-1606 
Correira F, Santos M, Rodrigues R (1987) Engineering risk in regional drought studies. In: Duckstein L, Plate EJ (eds) Engineering reliability and risk in water resources. Nijhoff M, Dordrecht/Boston, pp 61 - 86

Corell R, Cramer W, Schellnhuber HJ Methods and models of vulnerability research, analysis and assessment. In: Symposium at Potsdam Sustainability Days, Potsdam, 2001.

Crichton D (1999) The risk triangle. In: Ingleton J (ed) Natural disaster management. Tudor Rose, London, pp $102-103$

CrisisMappers (2012) The humanitarian technology network. Available online at http://crisismappers.net/ Accessed 12 Jul 2012

Crowley H, Bommer J (2006) Modelling seismic hazard in earthquake loss models with spatially distributed exposure. Bulletin of Earthquake Engineering 4:249-273

Crowley H, Pinho R, Bommer JJ (2004) A probabilistic displacement-based vulnerability assessment procedure for earthquake loss estimation. Bulletin of Earthquake Engineering 2:173-219

Crowley H, Pinho R, Bommer JJ, Bird JF (2006) Development of a displacement-based method for earthquake loss assessment. Report 2006/01. European School for Advanced Studies in Reduction of Seismic Risk (ROSE School), Pavia, Italy

CSA (2012) Canadian Space Agency - RADARSAT Mission description. Available online at http://www.asccsa.gc.ca/eng/satellites/radarsat/description.asp Accessed 8 May 2012

Cunningham D, Grebby S, Tansey K, Gosar A, Kastelic V (2006) Application of airborne LiDAR to mapping seismogenic faults in forested mountainous terrain, southeast Alps, Slovenia. Geophysical Research Letters 33:L20308, doi:20310.21029/22006GL027014

Cutter S (2003) Social Vulnerability to Environmental Hazards. Social Science Quarterly 84 (2):242 - 261

Cutter S, Emrich C, Webb J, Morath D (2009) Social vulnerability to climate variability hazards: A review of the literature. Final Report to Oxfam America

Cutter SL (1996) Vulnerability to environmental hazards. Progress in Human Geography 20(4):529 - 539

Daniell J (2009) Open source Procedure for assessment of loss using global earthquake modelling - OPAL-GEM Project. CEDIM Research Report 09/01. Karlsruhe, Germany

Daniell JE (2011) Open source procedure for assessment of loss using global earthquake modelling software (OPAL). Natural Hazards and Earth System Sciences 11:1885-1900

Davidson R (1997) An urban earthquake disaster risk index. John A. Blume Earthquake Engineering Center, Department of Civil Engineering. Stanford University, Stanford

Dech S (1997) Anwendung der Satellitenfernerkundung. Von der geowissenschaftlichen Forschung zum operationellem Einsatz. DLR-Forschungsbericht 97, 52

Deichmann U, Ehrlich D, Small C, Zeug G (2011) Using high resolution satellite data for the identification of urban natural disaster risk. Global Facility for Disaster Reduction and Recovery: Washington, DC, USA, 80p.

Dell'Acqua F, Lisini G, Gamba P (2009) Experiences in optical and SAR imagery analysis for damage assessment in the Wuhan, May 2008 Earthquake. IEEE International Geoscience and Remote Sensing Symposium 2009, Vols 1-5: 2417-2420

Demirkesen AC (2008) Digital terrain analysis using Landsat-7 ETM+ imagery and SRTM DEM: a case study of Nevsehir province (Cappadocia), Turkey. International Journal of Remote Sensing 29:4173-418

Deng X, Jiang Q, Ge Q, Yang L (2010) Impacts of the Wenchuan earthquake on the Giant Panda nature reserves in China. Journal of Mountain Science 7:197-206

DESDynI (2011) Deformation, Ecosystem Structure and Dynamics of Ice - Mission concept. Available online at http://desdyni.jpl.nasa.gov/mission/ Accessed 7 Oct 2011

DigitalGlobe (2012) WorldView-3. Available online at http:/www.digitalglobe.com/downloads/WorldView3DS-WV3-Web.pdf Accessed 24 May 212

Dilley M, Chen RS, Deichmann U, Lerner-Lam AL, Arnold M, Agwe J, Buys P, Kjekstad O, Lyon B, Yetman G (eds) (2005) Natural disaster hotspots. A global risk analysis, vol 5. Disaster risk management series. The World Bank Hazard Management Unit, Washington D.C.

Ding X, Huang W (2011) D-InSAR monitoring of crustal deformation in the eastern segment of the Altyn Tagh Fault. International Journal of Remote Sensing 32:1797-1806

DLR-ZKI (2010) Earthquakes in Haiti on January 12, 2010. Available online at http://www.zki.dlr.de/article/1262 Accessed 24 Jun 2011

Dobson JE, Bright EA, Coleman PR, Durfee RC, Worley BA (2000) LandScan: A global population database for estimating populations at risk. Photogrammetric Engineering and Remote Sensing 66:849-857

Dominguez S, Avouac JP, Remi M (2003) Horizontal coseismic deformation of the 1999 Chi-Chi earthquake measured from SPOT satellite images: Implications for the seismic cycle along the western foothills of central Taiwan. Journal of geophysical research 108 (0.1029/2001JB000951)

Downing TE, Butterfield R, Cohen S, Huq S, Moss R, Rahman A, Sokona Y, Stephen L (2001) Vulnerability indicies: Climate change impacts and adaption. Policy Series 3. United Nations Development Programme, Nairobi, Kenya. 
Duarah BP, Phukan S (2011) Understanding the tectonic behaviour of the Shillong plateau, India using remote sensing data. Journal of the Geological Society of India 77:105-112

Ebert A, Kerle N, Stein A (2009) Urban social vulnerability assessment with physical proxies and spatial metrics derived from air- and spaceborne imagery and GIS data. Natural Hazards 48:275-294

e-GEOS (2012) e-GEOS: Emergency Response Mapping. Available online at http://www.eurimage.com/applications/emergency.html Accessed 11 Jul 2012

Ehrlich D, Guo H, Molch K, Ma JW, Pesaresi M (2009) Identifying damage caused by the 2008 Wenchuan earthquake from VHR remote sensing data. International Journal of Digital Earth 2(4):309-326

Ehrlich D, Zeug G (2008) Assessing disaster risk of building stock. Methodology based on earth observation and geographical information systems. JRC Scientific and Technical Reports. European Comission Joint Research Centre - Institute for the Protection and Security of the Citizen.

Ehrlich D, Zeug G, Gallego J, Gerhardinger A, Caravaggi I, Pesaresi M (2010) Quantifying the building stock from optical high-resolution satellite imagery for assessing disaster risk. Geocarto International 25 (4):281-293

EMCA (2011) Earthquake Model Central Asia. Available online at http://www.emca-gem.org/ Accessed 21 Sep 2011

EMME (2011) Earthquake Model of the Middle East Region. Available online at http://www.emme-gem.org/ Accessed 21 Sep 2011

Eineder M, Friedrich A, Minet C, Bamler R, Flerit F, Hajnsek I (2009) Scientific requirements and feasibility on an L-band mission dedicated to measure surface deformation. IEEE International Geoscience and Remote Sensing Symposium, 12.-17. July 2009, Cape Town, South Afrika

Eineder M, Yague-Martinez N, Minet C, Fritz T, Parizzi A (2010) Haiti earthquake surface shift estimation using TerraSAR-X data. Available online at http://supersites.earthobservations.org/TerraSAR-X-DLR01-27.pdf Accessed 5 Jul 2011

Erdik M, Demircioglu M, Sesetyan K, Durukal E, Siyahi B (2004) Earthquake hazard in Marmara Region, Turkey. Soil Dynamics and Earthquake Engineering 24:605-631

Erten E, Reigber A, Hellwich O (2010) Generation of three-dimensional deformation maps from InSAR data using spectral diversity techniques. ISPRS Journal of Photogrammetry and Remote Sensing 65:388-394

ESA (2011) GMES Sentinels - Sentinels Overview. Available online at http://www.esa.int/esaLP/SEM097EH1TF_LPgmes_0.html Accessed 30 Sep 2011

ESA II (2012) ESA - Insurance workshop on earth observation (Natural Catastrophes). Workshop Summary Report, Esrin, Italy, 23-24 Feb 2012. Available online at http://earth.eo.esa.int/workshops/Insurance/files/Insurance_Industry_EO_wshop_report_FINAL.pdf Accessed 13 Jul 2012

Esch T, Dech S, Roth A, Schmidt M, Taubenböck H, Heldens W, Thiel M, Wurm M, Klein D (2009) Monitoring and assessment of urban environments using space-borne earth observation data. In: Kreck A, Rumor M, Zlatanova S, Fendel E (eds) Urban and Regional Data Management. Taylor\&Francis Group, London, pp 385-398

Esch T, Thiel M, Schenk A, Roth A, Müller A, Dech S (2010) Delineation of urban footprints from TerraSAR-X data by analyzing speckle characteristics and intensity information. IEEE Transactions on geoscience and remote sensing 48(2):905-916

Fekete, A. (2011). Spatial disaster vulnerability and risk assessments: challenges in their quality and acceptance. Natural Hazards. doi:10.1007/s11069-011-9973-7

Fekete A, Hufschmidt G (2012) Atlas of Vulnerability and Resilience Research: Case studies for Germany, Austria and Schwitzerland, to be published.

FEMA (2010) HAZUS - MH MR5. Multi-hazard loss estimation methodology - earthquake model. Technical manual. Department of Homeland Security, Emergency Prepardness and Response Directorate. Washington, D.C.

Fielding EJ, Wright TJ, Muller J, Parsons BE, Walker R (2004) Aseismic deformation of a fold-and-thrust belt imaged by synthetic aperture radar interferometry near Shahdad, southeast Iran. Geology 32(7):577-580

Fornaro G, Pauciullo A, Serafino F (2009) Deformation monitoring over large areas with multipass differential SAR interferometry: a new approach based on the use of spatial differences. International Journal of Remote Sensing 30:1455-1478

Forsyth T (2004) Critical political ecology: The politics of environmental science. Routledge, London

Freeman AS (2004) Review of the development of the capacity spectrum method. ISET Journal of Earthquake Technology 41(1):1-13

French SP, Muthukumar S (2006) Advanced technologies for earthquake risk inventories. Journal of Earthquake Engineering 10 (2):207-236

Fu B, Ninomiya Y, Lei X, Toda S, Awata Y (2004) Mapping active fault associated with the $2003 \mathrm{Mw} 6.6 \mathrm{Bam}$ (SE Iran) earthquake with ASTER 3D images. Remote Sensing of Environment 92:153-157

Fuchs S (2009) Susceptability versus resilience to mountain hazards in Austria - Paradigms of vulnerability revisited. Natural Hazards and Earth System Sciences 9:337-352 
Fuchs S, Kuhlicke C, Meyer V (2011) Editorial for the special issue: vulnerability to natural hazards - the challenge of integration. Natural Hazards 58:609-619

Füssel HM (2007) Vulnerability: A generally applicable conceptual framework for climate change research. Global Environmental Change-Human and Policy Dimensions 17: 155-167

Füssel HM, Klein RJT (2006) Climate change vulnerability assessments: An evolution of conceptual thinking. Climatic Change 75:301-329

Füssel HM (2005) Vulnerability in climate change research: A comprehensive conceptual framework. University of California, International and Area Studies. Breslauer Symposium No. 6, Paper 6

Gamba P, Aldrighi M, Stasolla M (2011) Robust Extraction of Urban Area Extents in HR and VHR SAR Images. IEEE Journal of Selected Topics in Applied Earth Observation and Remote Sensing 4(1):27-34

Gamba P, Dell'Acqua F, Trianni G (2007) Rapid damage detection in the Bam area using multitemporal SAR and exploiting ancillary data. IEEE Transactions on geoscience and remote sensing 45(6):1582-1589

Garatwa W, Bollin C (2002) Disaster Risk Management: Working Concept. GTZ - Gesellschaft für technische Zusammenarbeit, Eschborn, Germany.

Ge Y, Xu J, Liu Q, Yao Y, Wang R (2009) Image interpretation and statistical analysis of vegetation damage caused by the Wenchuan earthquake and related secondary disasters. Journal of Applied Remote Sensing 3, 031660 (26 May 2009). doi: 10.1117/1.3141726

GEM (2011) Global Earthquake Model. Available online at http://www.globalquakemodel.org/ Accessed 21 Sep 2011

GEO (2011) Group on earth observations. Disasters: Strategic Target. Available online at http://www.earthobservations.org/geoss_di_tar.shtml Accessed 17 Oct 2011

GeoNode (2012) GeoNode Online Platform. Available online at http://geonode.org/ Accessed 18 Jul 2012

GFDRR (2011) Global facility for disaster reduction and recovery. Available online at http://www.gfdrr.org/gfdrr/ Accessed 17 Oct 2011

GFDRR (2012) GFDRR Case Study: Central American Probabilistic Risk Assessment (CAPRA). Available online at http://www.gfdrr.org/docs/Snapshot_CAPRA.pdf Accessed 18 Jul 2012

GIO (2012) GMES Initial Operations (GIO). Available online at http://portal.emsgmes.eu/web/guest;jsessionid=a5adb6c432f96a27da343aee7a81 Accessed 21 Sep 2011

Girgin S (2011) The natech events during the 17 August 1999 Kocaeli earthquake: aftermath and lessons learned. Natural Hazards and Earth System Sciences 11(4):1129-1140

Gitas IZ, Polychronaki A, Katagis T, Mallinis G (2008) Contribution of remote sensing to disaster management activities: A case study of the large fires in the Peloponnese, Greece. Int J Remote Sens 29 (6):18471853

G-MOSAIC (2012) G-MOSAIC: GMES Pilot Services for Security. Available online at http://www.gmesgmosaic.eu/ Accessed 12 Jul 2012

Gonzalez PJ, Chini M, Stramondo S, Fernandez J (2010) Coseismic horizontal offsets and fault-trace mapping using phase correlation of IRS satellite images: The 1999 Izmit (Turkey) earthquake. IEEE Transactions on geoscience and remote sensing 48:2242-2250

Google (2012) Google Map Maker. Available online at http://www.google.com/mapmaker Accessed 12 Jul 2012

Gorny VI, Salman AG, Tronin AA, Shilin BV (1988) The earth's outgoing IR radiation as an indicator of seismic activity. Proc Acad Sci USSR 301:67-69

Granger K (2003) Quantifying storm tide risk in cairns. Natural Hazards 30:165-185

Gravely D (2001) Risk, hazard and disaster. University of Canterbury, New Zealand.

Green C (2004) The evaluation of vulnerability to flooding. Disaster Prevention and Management 13(4):323 329

Grünthal G, Musson R, Schwarz J, Stucchi M (1998) European Macroseismic Scale. Cahiers de Centre Européen de Géodynamique et de Seismologie, vol 15, Luxembourg

Guinau M, Pallas R, Vilaplana JM (2005) A feasible methodology for landslide susceptibility assessment in developing countries: A case-study of NW Nicaragua after Hurricane Mitch. Engineering Geology 80(3-4):316-327

Guo H (2009) Guest editorial: Remote sensing of the Wenchuan earthquake. Journal of Applied Remote Sensing 3:031699 (26 May 2009). doi: 10.1117/1.3153899

Guo H (2010) Understanding global natural disasters and the role of earth observation. International Journal of Digital Earth 3(3):221-230

Guo HD, Ma JW, Zhang B, Li Z, Huang J, Zhu LW (2010) Damage consequence chain mapping after the Wenchuan earthquake using remotely sensed data. Int J Remote Sens 31(13):3427-3433

Gup G, Xie G (2007) Earthquake cloud over Japan detected by satellite. Int J Remote Sens 28(23):5375-5376

Hahn H (2003) Indicators and other instruments for local risk management for communities and local governments. Document prepared as part of the documents related to the Project Local Risk Management for Communities and Local Governments. The German Technical Cooperation Agency (GTZ) for IADB. 
Han S-C, Shum CK, Bevis M, Ji C, Kuo C-Y (2006) Crustal dilatation observed by GRACE after the 2004 Sumatra-Andaman earthquake. Science 313:658-662

Han Y, Liu H, Cui P, Su F, Du D (2009) Hazard assessment on secondary mountain-hazards triggered by the Wenchuan earthquake. Journal of Applied Remote Sensing 3: 031645 (26 May 2009). doi:031645031645-031616

Heipke C (2010) Crowdsourcing geospatial data. ISPRS Journal of Photogrammetry and Remote Sensing 65:550-557

Heldens W, Heiden U, Esch T, Stein E, Müller A (2011) Can the Future EnMAP Mission Contribute to Urban Applications? A Literature Survey. Remote Sens 3(9):1817-1846

Heltberg R, Siegel PB, Jorgensen SL (2009) Addressing human vulnerability to climate change: Toward a 'noregrets' approach. Global Environmental Change-Human and Policy Dimensions 19(1):89-99

Hilhorst D, Bankoff G (2004) Mapping vulnerability. In: Bankoff G, Frerks G, Hilhorst D (eds) Mapping vulnerability. Disasters, Development \& Peolpe. Eartscan, London, pp 1-24

Hoffmann J (2007) Mapping damage during the Bam (Iran) earthquake using interferometric coherence. Int J Remote Sens 28(6):1199-1216

Hong Y, Adler R, Huffmann G (2007) Use of satellite remote sensing data in the mapping of global landslide susceptibility. Natural Hazards 43:245-256

HOSMT (2012) Humanitarian Open Street Map Team. Available online at http://hot.openstreetmap.org/ Accessed 12 Jul 2012

Huang RQ, Li WL (2009) Analysis of the geo-hazards triggered by the 12 May 2008 Wenchuan Earthquake, China Bulletin of Engineering Geology and the Environment 68(3):363-371

Huang X, Wei C, Li H (2009) Remote sensing analysis of the distribution and genetic mechanisms of transportation network damage caused by the Wenchuan earthquake. Journal of Applied Remote Sensing 3: 031650 (26 May 2009). doi: 10.1117/1.3154387

Hufschmidt G (2011) A comparative analysis of several vulnerability concepts. Natural Hazards 58:621-643

ICSMD (2011a) Earthquake in Japan. Available online at http://www.disasterscharter.org/web/charter/activation_details?p_r_p_1415474252_assetId=ACT-359 Accessed 25 Sep 2011

ICSMD (2011b) International Charter on Space and Major Disasters. Charter On Cooperation To Achieve The Coordinated Use Of Space Facilities In The Event Of Natural Or Technological Disasters Rev.3 (25/4/2000).2. Available online at http://www.disasterscharter.org/web/charter/charter Accessed 25 Sep 2011

ICSU (2011) International Council for Science. Disaster risk - integrated research on disaster risk. Available online at http://www.icsu.org/what-we-do/interdisciplinary-bodies/irdr Accessed 17 Oct 2011

IDRC (2011) International disaster risk conference. Available online http://www.idrc.info/ Accessed 17 Oct 2011

IFRC (1999) Vulnerability and capacity assessment: An international federation guide. Geneva, Switzerland

INSPIRE (2012) Infrastructure for Spatial Information in the European Community. Available online at http://inspire.jrc.ec.europa.eu/ Accessed 13 Jul 2012

InSTEDD (2012) Innovative Support to Emergencies Diseases and Disasters. Available online at http://instedd.org/ Accessed 12 Jul 2012

Jaiswal K, Wald D, D'Ayala D (2011) Developing Empirical Collapse Fragility Functions for Global Building Types. Earthquake Spectra 27(3):775-795

Jaiswal K, Wald D, Porter K (2010) A global building inventory for earthquake loss estimation and risk management. Earthquake Spectra 26:731-748

Janssen AM, Ostrom E (2006) Resilience, vulnerability, and adaption: A cross-cutting theme of the International Human Dimensions Programme on Global Environmental Change (editorial). Global Environmental Change 16:237-239

JAXA (2011) Advanced Land Observing Satellite-2. Available online at http://www.jaxa.jp/projects/sat/alos2/index_e.html Accessed 7 Oct 2011

Joyce K, Belliss S, Samsonov S, McNeill S, Glassey P (2009) A review of the status of satellite remote sensing and image processing techniques for mapping natural hazards and disasters. Progress in Physical Geography 33(2): $183-207$

Joyce K, Wright K, Samsonov S (2009) Remote sensing and the disaster management cycle. In: Jedlovec G (ed) Advances in Geoscience and Remote Sensing vol. 48, 7. INTECH, pp 317 - 346

Kakinami Y, Liu JY, Tsai LC, Oyama KI (2010) Ionospheric electron content anomalies detected by a FORMOSAT-3/COSMIC empirical model before and after the Wenchuan Earthquake. International Journal of Remote Sensing 31:3571-3578

Kasperson J, Kasperson R, Turner BL, Hsieh W, Schiller A (2005) Vulnerability to Global Environmental Change. In: Kasperson J, Kasperson R (eds) The social contours of risk. Volume II: Risk Analysis, Corporations \& the Globalization of Risk. Earthscan, London, pp 245 - 285 
Katti RV, Thyagarajan K, Shankara NK, Kiran Kumar SA (2007) Spacecraft technology, Special section: Indian space programme. Current Science 93(12):1715-1736

Kaya S, Curran PJ, Llewellyn G (2005) Post-earthquake building collapse: a comparison of government statistics and estimates derived from SPOT HRVIR data. Int J Remote Sens 26(13):2731-2740

Kaya S, Muftuoglu O, Tuysuz O (2004) Tracing the geometry of an active fault using remote sensing and digital elevation model: Ganos segment, North Anatolian Fault zone, Turkey. Int J Remote Sens 25 (19):38433855

Kerle N (2010) Satellite-based damage mapping following the 2006 Indonesia earthquake--How accurate was it? International Journal of Applied Earth Observation and Geoinformation 12(6):466-476

Korup O (2010) COGEAR - Coupled seismogenic geohazards in alpine regions. Module 1: Earthquake-triggered landslides - spatial patterns and impacts. Swiss Federal Research Institutes WSL/SLF, Davos, Switzerland.

Kosugi Y, Sakamoto M, Fukunishi M, Lu W, Doihara T, Kakumoto S (2004) Urban Change Detection Related to Earthquakes Using an Adaptive Nonlinear Mapping of High-Resolution Images. IEEE Geosci Remote Sens Lett 1(3):152-156

Kumar KV, Martha TR, Roy PS (2006) Mapping damage in the Jammu and Kashmir caused by 8 October 2005 Mw 7.3 earthquake from the Cartosat-1 and Resourcesat-1 imagery. Int J Remote Sens 27(20):44494459

Kuzuoka S, Mizuno T (2004) Land deformation monitoring using PSInSAR technique. In: Proceedings of International Symposium on Monitoring, Prediction and Mitigation of Disasters by Satellite Remote Sensing, Awaji, Hyogo, Japan, January 2004, pp 176-181.

Lafond G, Gosselin A (1994) A survey on perceived risks. In: Martin LRG (ed) Risk assessment and management: emergency planning perspectives. pp 44-59

Lang S, Tiede D (2010) Rapid geospatial reporting. Erfahrungen mit automatisierter Schadensanalyse nach den Erdbeben in Haiti und Chile. GIS Business, 2:42-43

Leprince S, Ayoub F, Klinger Y, Avouac JP (2007) Co-registration of optically sensed images and correlation (COSI-Corr): an operational methodology for ground deformation measurements. IEEE International Geoscience and Remote Sensing Symposium, July 2007, Barcelona, Spain, pp 1943-1946

Lewis J (1999) Development in disaster-prone places: Studies of vulnerability. Intermediate Technology Publications. Intermediate Technology Publications, London

Li M, Cheng L, Gong J, Liu Y, Chen Z, Li F, Chen G, Chen D, Song X (2008) Post-earthquake assessment of building damage degree using LiDAR data and imagery. Science in China Series E: Technological Sciences 51:133-143

Li P, Xu H, Guo, J (2010) Urban building damage detection from very high resolution imagery using OCSVM and spatial features. International Journal of Remote Sensing, 31:3393-3409

LinkER (2012) linkER -Supporting the implementation of operational GMES services in Emergency Response. Available online at http://www.zki.dlr.de/project/1394 Accessed 8 May 2012

Liou YA, Kar SK, Chang L (2010) Use of high-resolution FORMOSAT-2 satellite images for post-earthquake disaster assessment: a study following the 12 May 2008 Wenchuan Earthquake. International Journal of Remote Sensing 31:3355-3368

Liu JG, Haselwimmer, CE (2006) Co-seismic ruptures found up to $60 \mathrm{~km}$ south of the Kunlun fault after 14 November 2001, Ms 8.1, Kokoxili earthquake using Landsat-7 ETM+ imagery. International Journal of Remote Sensing 27:4461-4470

López-Dekker P, Prats P, De Zan F, Schulze D, Krieger G, Moreira A (2011) TanDEM-X first DEM Acquisition: A crossing orbit experiment. IEEE Geoscience and remote sensing letters 8(5):943-947

Lundgren P, Casu F, Manzo M, Pepe A, Berardino P, Sansosti E, Lanari R (2004) Gravity and magma induced spreading of Mount Etna volcano revealed by satellite radar interferometry. Geophysical Research Letters 31, L04602. doi: 10.1029/2003GL018736

Maeda T, Takano T (2010) Detection Algorithm of Earthquake-Related Rock Failures From Satellite-Borne Microwave Radiometer Data. IEEE Transactions on geoscience and remote sensing 48(4):1768-1776

Marsan D, Lengline O (2008) Extending earthquakes' reach through cascading. Science 319 (5866):1076-1079

Massonnet D (1995) Application of remote sensing data in earthquake monitoring. Advances in Space Research 15(11):37-44

Massonnet D, Feigl K (1998) Radar interferometry and its application to changes on the earth surface. Reviews of Geophysics 36:441-500

Massonnet D, Rossi M, Carmona C, Adragna F, Peltzer G, Feigl K, Rabaute T (1993) The displacement field of the Landers earthquake mapped by radar interferometry. Nature 364:138-142

Masure P (2003) Variables and indicators of vulnerability and disaster risk for land-use and urban or territorial planning. Information and indicators program for disaster risk management, IADB - ECLAC - IDEA.

Matsuoka, M., \& Yamazaki, F. (2010).Comparative analysis for detecting areas with building damage from several destructive earthquakes using satellite synthetic aperture radar images. Journal of Applied Remote Sensing 4: 041867 (18 Nov 2010). doi: 10.1117/1.3525581 
McCloskey J, Nalbant SS, Steacy, S (2005) Indonesian earthquake: Earthquake risk from co-seismic stress. Nature 434:291-291

Menoni S, Pergalani F, Boni MP, Petrini V (2002) Lifelines earthquake vulnerability assessment: a systemic approach. Soil Dynamics and Earthquake Engineering 22(9-12):1199-1208

Mercer J, Dominey-Howes D, Kelman I, Lloyd K (2007) The potential for combining indigenous and western knowledge in reducing vulnerability to environmental hazards in small island developing states. Environmental Hazards 7(4):245-256

Minet C, Eineder M, Bamler R, Hajnsek I, Friedrich A (2008) Requirements for an L-band SAR-Mission for global monitoring of tectonic activities. USEReST '08, 11-14 November 2008, Naples, Italy

Mitomi H, Matsuoka M, Yamazaki F (2002) Application of automated damage detection of buildings due to earthquakes by panchromatic television Images. Proceedings of the 7th U.S. National Conference on Earthquake Engineering, Boston.

Möller M (2011) Systemvergleich hochauflösender optischer Satellitenfernerkundungssensoren. In: Strobl J, Blaschke T, Griesebner G (eds) Angewandte Geoinformatik 2011, Beiträge zum 23. AGIT-Symposium Salzburg, 2011. Wichmann Verlag, Heidelberg.

Moreira A, Krieger G, Younis M, Hajnsek I, Papathanassiou K, Eineder M, De Zan F (2011) Tandem-L: A mission proposal for monitoring dynamic earth processes. IEEE International Geoscience and Remote Sensing Symposium, 25-29 July 2011, Vancouver, Canada

Motagh M, Schurr B, Anderssohn J, Cailleau B, Walter T R, Wang R, Villotte J P, (2010) Subduction earthquake deformation associated with 14 November 2007, Mw 7.8 Tocopilla earthquake in Chile: Results from InSAR and aftershocks. Tectonophysics, 490, 1-2, 66-68.

Mueller M, Segl K, Heiden U, Kaufmann H (2006) Potential of high-resolution satellite data in the context of vulnerability of buildings. Natural Hazards 38:247-258

Müller A, Reiter J, Weiland U (2011) Assessment of urban vulnerability towards floods using an indicator-based approach - a case study for Santiago de Chile. Natural Hazards and Earth System Sciences 11:21072123

Munich Re Group (2011). Topics geo, natural catastrophes 2008 - Analyses, assessments, positions. Available online at http://www.amre.com/pdf/topicsgeo_2008.pdf Accessed 19 Sep 2011

Nassel M, Voigt S (2006) Vulnerability assessment of the built environment. In: Birkmann J, Fernando N, Hettige S, Amarasinghe S, Jayasingham T, Paranagama D, Nandana MDA, Nassel M, Voigt S, Grote U, Engel S, Schraven B, Wolferts J (eds) Rapid and multidimensional vulnerability assessment in Sri Lanka at the local level, UNU-EHS. Colombo, Bonn, pp 10-22.

Neer JT (1999) High resolution imaging from space - A commercial perspective on a changing landscape. International Archives of Photogrammetry and Remote Sensing XXXII (7C2):132-143

O'Brien K, Leichenko R, Kelkar U, Venema H, Aandahl G, Tompkins H, Javed A, Bhadwal S, Barg S, Nygaard L, West J (2004) Mapping vulnerability to multiple stressors: climate change and globalization in India. Global Environmental Change-Human and Policy Dimensions 14(4):303-313

OGC (2012) Open Geospatial Consortium. Available online at http://www.opengeospatial.org/ Accessed 8 May 2012

O'Keefe P, Westgate K, Wisner B (1976) Taking the naturalness out of natural disasters. Nature 260:566-567

Ouzounov D, Bryant N, Logan T, Pulinets S, Taylor S (2006) Satellite thermal IR phenomena associated with some of the major earthquakes in 1999-2003. Physics and Chemistry of the Earth, Parts A/B/C 31(49):154-163

Ouzounov D, Freund F (2004) Mid-infrared emission prior to strong earthquakes analyzed by remote sensing data. Advances in Space Research 33(3):268-273

Ouzounov D, Liu D, Kang C, Cervone G, Kafatos M, Taylor P (2007) Outgoing long wave radiation variability from IR satellite data prior to major earthquakes. Tectonophysics 431:211-220

Ozawa S, Murakami M, Fujiwara S, Tobita M (1997) Synthetic aperture radar interferogram of the 1995 Kobe earthquake and its geodetic inversion. Geophysical Research Letters 24(18):2327-2330

Panza GF, Irikura K, Kouteva M, Peresan A, Wang Z, Saragoni R (2011) Advanced Seismic Hazard Assessment. Pure and Applied Geophysics 168:1-9

Parsons T (2004) Recalculated probability of $M \geq 7$ earthquakes beneath the Sea of Marmara, Turkey. Journal of Geophysical Research 109, B05304

Paylor II ED, Evans DL, Tralli DM (2005) Remote sensing and geospatial information for natural hazards characterization. ISPRS Journal of Photogrammetry \& Remote Sensing 59:181-184

Peduzzi P (2006) The disaster risk index: Overview over a quantitative approach In: Birkmann J (ed) Measuring vulnerability to natural hazards - Towards disaster resilient societies. United Nations University, New York, pp 171-181

Peduzzi P, Dao H, Herold C (2005) Mapping disastrous natural hazards using global datasets. Natural Hazards 35:265-289

Peduzzi P, Dao H, Herold C, Mouton F (2009) Assessing global exposure and vulnerability towards natural hazards: the Disaster risk index. Natural Hazards and Earth System Sciences 9(4):1149-1159 
Pelling M (2003) The vulnerability of cities - Natural disasters and social resilience. Earthscan Publications Ltd., London

PERILS (2012) PERILS AG. Available online at http://www.perils.org/ Accessed 17 Jul 2012

Pesaresi M, Ehrlich D, Caravaggi I, Kauffmann M, Louvrier C (2011) Toward Global Autmatic Built-Up Area Recognition Using Optical VHR Imagery. IEEE Journal of Selected Topics in Applied Earth Observatins and Remote Sensing 4(4):923-934

Pesaresi M, Gerhardinger A (2011) Improved textural built-up presence for automatic recognition of human settlements in arid regions with scattered vegetation. IEEE Journal of selected topics in applied earth observation and remote sensing 4(1): 16-26

Pesaresi M, Gerhardinger A, Haag F (2007) Rapid damage assessment of built-up structures using VHR satellite data in tsunami-affected areas. Int J Remote Sens 28(13-14):3013-3036

Philip G (2010) Remote sensing data analysis for mapping active faults in the northwestern part of Kangara Valley, NW Himalaya, India. Int J Remote Sens 28 (21):4745-4761

Pinar A, Honkura, Y., Kuge K (2001) Seismic activity triggered by the 1999 Izmit earthquake and its implications for the assessment of future seismic risk. Geophysical Journal International 146(1):F1-F7

Plaza AJ, Chang C-I (2008) High Performance Computing in Remote Sensing. Chapman \& Hall/CRC: Boca Raton, Fl., 466 pp.

Polli D, Dell'Acqua F (2011) Fusion of optical and SAR data for seismic vulnerability mapping of buildings In: Prasad S, Bruce LM, Chanussot J (eds) Optical remote sensing. Advances in signal processing and exploitation techniques. Springer, Heidelberg, pp 329-341

Prasad JSR, Singh Y, Kaynia AM, Lindholm C (2009) Socioeconomic clustering in seismic risk assessment of urban housing stock. Earthquake Spectra 25:619-641

PreView 2012 PreView: Geo-information services for risk management on a European level. Available online at http://www.preview-risk.com/site/FO/scripts/myFO_accueil.php?flash=1\&lang=EN Accessed 12 Jul 2012

Ramm F, Topf J, Chilton S (2010) OpenStreetMap: Using and Enhancing the Free Map of the World. Uit Cambridge Ltd. 352 pp.

Rashed T, Weeks J (2003) Assessing vulnerability to earthquake hazards through spatial multicriteria analysis of urban areas. Int J Geogr Inf Sci 17(6):547-576

Rathje EM, Adams BJ (2008) The role of remote sensing in earthquake science and engineering: Opportunities and challenges. Earthquake Spectra 24(2):471-492

Reale D, Nitti DO, Peduto D, Nutricato R, Bovenga F, Fornaro G (2011) Postseismic deformation monitoring with the COSMO/SKYMED constellation. IEEE Geoscience and remote sensing letters 8:696-700

Reif D, Grasemann B, Faber RH (2011) Quantitative structural analysis using remote sensing data: Kurdistan, northeast Iraq. Aapg Bulletin 95:941-956

Remi M, Avouac JP (2002) Deformation due to the 17 August 1999 Izmit, Turkey, earthquake measured from SPOT images. Journal of geophysical research 107. doi:10.1029/2000JB000102

RIMS (2012) The Risk Management Society. Available online at http:/www.rims.org/Pages/Default.aspx Accessed 20 Jul 2012

RiskScape (2012) Easy-to-use multi-hazard impact and risk assessment tool. Available online at http://www.globalquakemodel.org/ Accessed 21 Sep 2011

Robinson D, Dhu T, Schneider J (2006) Practical probabilistic seismic risk analysis: A demonstration of capability. Seismological Research Letters 77 (4):453-459

Roessner S, Wetzel H-U, Kaufmann H, Sarnagoev A (2005) Potential of satellite remote sensing and GIS for landslide hazard assessment in Southern Kyrgyzstan (Central Asia). Natural Hazards 35:395-416

Rosenau M, Nerlich R, Brune S, Oncken O (2010) Experimental insights into the scaling and variability of local tsunamis triggered by giant subduction megathrust earthquakes. Journal of Geophysical Research-Solid Earth 115. doi: B09314 10.1029/2009jb007100

SAFER (2011) Services and Applications For Emergency Response. Available online at http://safer.emergencyresponse.eu/site/FO/scripts/myFO_accueil.php?lang=EN Accessed 21 Sep 2011

Sahal A, Roger J, Allgeyer S, Lemaire B, Hebert H, Schindele F, Lavigne F (2009) The tsunami triggered by the 21 May 2003 Boumerdes-Zemmouri (Algeria) earthquake: field investigations on the French Mediterranean coast and tsunami modelling. Natural Hazards and Earth System Sciences 9(6):18231834

Sahar L, Muthukumar S, French P (2010) Using aerial imagery and GIS in automated building footprint extraction and shape recognition for earthquake risk assessment of urban inventories. IEEE Transactions on geoscience and remote sensing 48(9):3511-3520

Saito K, Spence R (2004) Rapid damage mapping using post-earthquake satellite images. In: IEEE International Geoscience and Remote Sensing Symposium, August 2004, Anchorage, AK, USA, pp 2272 - 2275

Salvi S, Stramondo S, Funning GJ, Ferretti A, Sarti F, Mouratidis A (2012) The Sentinel-1 mission for the improvement of the scientific understanding and the operational monitoring of the seismic cycle. Remote Sensing of Environment 120:164-174 
Samuels P, Gouldby B, Klijn F, Messner F, van Os A, Sayers P, Schanze J, Udale-Clarke H (2009) Language of risk - project definitions. Floodsite project report T32-04-01.

Saradjian MR, Akhoondzadeh M (2011) Thermal anomalies detection before strong earthquakes $(\mathrm{M}>6.0)$ using interquartile, wavelet and Kalman filter methods. Natural Hazards and Earth System Sciences 11:10991108

Saraf AK (2000) IRS-1C-PAN Depicts Chamoli earthquake induced landslides in Garhwal Himalayas, India. Int J Remote Sens 21:2345-2352

Saraf AK, Choudhury S (2005) Thermal Remote Sensing Technique in the Study of Pre-Earthquake Thermal Anomalies. J Ind Geophys Union 9(3):197-207

Saraf AK, Rawat V, Choudhury S, Dasgupta S, Das J (2009) Advances in understanding of the mechanism for generation of earthquake thermal precursors detected by satellites. International Journal of Applied Earth Observation and Geoinformation 11(6):373-379

Sarewitz D, Pielke R, Keykah M (2003) Vulnerability and risk; some thoughts from a political and policy perspective risk analysis. Risk Ana 23(4):805-810

Schmitt A, Wessel B, Roth A (2010) Curvelet-based change detection on SAR images for natural disaster mapping. Photogrammetrie Fernerkundung Geoinformation 6:463-474

Schneiderbauer S, Ehrlich D (2004) Risk, hazard and people's vulnerability to natural hazards. A review of definitions, concepts and data. Joint Research Centre, European Commission, EUR 21410

Schneiderbauer S, Ehrlich D (2006) Social levels and hazard (in)dependence in determining vulnerability. In: Birkmann J (ed) Measuring vulnerability to natural hazards. United Nations University Press, New York, pp 78-102

Sertel E, Kaya S, Curran PJ (2007) Use of semivariograms to identify earthquake damage in an urban area. IEEE Transactions on Geoscience and remote sensing 45(6):1590-1594

SERTIT (2012) SErvice Régional de Traitement d'Image et de Télédétection. Available online at http://sertit.ustrasbg.fr/english/en_welcome.htm Accessed 11 Jul 2012

SERVIR (2012) NASA Missions: SERVIR. Available online at http://www.nasa.gov/mission_pages/servir/index.html Accessed 11 Jul 2012

Setiadi N, Taubenböck H, Raupp S, Birkmann J (2010) Integrating socio-economic data in spatial analysis: An exposure analysis method for planning urban risk mitigation. 15th International Conference on Urban Planning and Regional Development in the Information Society, Vienna, Austria. GeoMultimedia 2010, pp. 367-374.

Shafique M, van der Meijde M, Ullah S (2011) Regolith modeling and its relation to earthquake induced building damage: A remote sensing approach. Journal of Asian Earth Sciences 42(1-2):65-75

Shafique M, van der Meijde M, van der Werff HMA (2012) Evaluation of remote sensing-based seismic site characterization using earthquake damage data. Terra Nova 24(2):123-129

Sinadinovski C, Edwards M, Corby N, Milne M, Dale K, Dhu T, Jones A, McPherson A, Jones T, Gray D, Robinson D, White J (2005) Earthquake risk. Natural hazard risk in Perth, WA, GeoCat No. 63527.

Singh RP (2010) Satellite observations of the Wenchuan Earthquake, 12 May 2008. Int J Remote Sens 31(10):3335-3339

Sitharam TG, Anbazhagan P, Ganesha Raj K (2006) Use of remote sensing and seismotectonic parameters for seismic hazard analysis of Bangalore. Natural Hazards and Earth System Sciences 6:927-939

Smit B, Wandel J (2006) Adaptation, adaptive capacity and vulnerability. Global Environmental Change 16(3):282-292

Smith K, Petley DN (2009) Environmental hazards - Assessing risk and reducing disaster. Routhledge

Smith W (2005) The challenge of earthquake risk. Seismological Research Letters 76(4):415-416

Stramondo S, Bignami C, Chini M, Pierdicca N, Tertulliani A (2006) Satellite radar and optical remote sensing for earthquake damage detection: results from different case studies. Int J Remote Sens 27 (20):44334447

Stramondo S, Moro M, Tolomei C, Cinti FR, Doumaz F (2005) InSAR surface displacement field and fault modelling for the 2003 Bam earthquake (southeastern Iran). Journal of Geodynamics 40:347-353

Stramondo S, Saroli M, Tolomei C, Moro M, Doumaz F, Pesci A, Loddo F, Baldi P, Boschi, E (2007) Surface movements in Bologna (Po Plain-Italy) detected by multitemporal DInSAR. Remote Sensing of Environment 110:304-316

Strunz G, Post J, Zosseder K, Wegscheider S, Mück M, Riedlinger T, Mehl H, Dech S, Birkmann J, Gebert N, Harjono H, Anwar HZ, Sumaryono, Khomarudin RM, Muhari A (2011) Tsunami risk assessment in Indonesia. Natural Hazards and Earth System Sciences 11:67-82

Suzuki S (2012) ALOS Program Status. Presentation held at meeting JAXA and DLR on 13 Jul 2012, Oberpfaffenhofen, Germany

Suzuki T, Miyoshi D, Meguro J, Amano Y, Hashizume T, Sato K, Takiguchi J (2008) Real-time hazard map generation using small unmanned aerial vehicle. Proceedings of SICE Annual Conference, Tokyo (Japan), 20-22 Aug 2008 
Tahayt A, Feigl K, Mourabit T, Rigo A, Reilinger R, McClusky S, Fadil A, Berthier E, Dorbath L, Serroukh M, Gomez F, Ben Sari D (2009) The Al Hoceima (Morocco) earthquake of 24 February 2004, analysis and interpretation of data from ENVISAT ASAR and SPOT5 validated by ground-based observations. Remote Sensing of Environment 113:306-316

Takano T, Maeda T (2009) Experiment and theoretical study of earthquake detection capability by means of microwave passive sensors on a satellite. IEEE Geosci Remote Sens Lett 6:107-111

Tang A, Wen A (2009) An intelligent simulation system for earthquake disaster assessment. Computers and Geosciences 35:871-879

Taubenböck H, Roth A, Dech S (2007) Linking structural urban characteristics derived from high resolution satellite data to population distribution. In: Coors V, Rumor M, Fendel E, Zlatanova S (eds) Urban and Regional Data Management. Taylor\&Francis Group, London, pp 35-45

Taubenböck H, Post J, Roth A, Zosseder K, Strunz G, Dech S (2008) A conceptual vulnerability and risk framework as outline to identify capabilities of remote sensing. Natural Hazards and Earth System Sciences 8:409-420

Taubenböck H, Goseberg N, Setiadi N, Lämmel G, Moder F, Oczipka M, Klüpfel H, Wahl R, Schlurmann T, Strunz G, Birkmann J, Nagel K, Siegert F, Lehmann F, dech S, Gress A, Klein R (2009b) "Last-Mile" preparation for a potential disaster - Interdisciplinary approach towards tsunami early warning and an evacuation information system for the coastal city of Padang, Indonesia. Natural Hazards and Earth System Sciences 9:1509-1528

Taubenböck H, Roth A, Dech S, Mehl H, Münich JC, Stempniewski L, Zschau J (2009a) Assessing building vulnerability using synergistically remote sensing and civil engineering. In: Kreck A, Rumor M, Zlatanova S, Fendel E (eds) Urban and Regional Data Management. Taylor\&Francis Group, London, pp 287-300

Taubenböck H (2011) The vulnerability of a city - diagnosis from a bird's eye view. Mörner N-A (ed) The Tsunami Threat - Research and Technology. InTech, Croatia, pp 107-128

Taubenböck H, Geiß C (2012) Vulnerability and resilience research - a critical perspective. Atlas of Vulnerability and Resilience Research: Case studies for Germany, Austria and Schwitzerland, to be published.

Teimouri M, Delavar MR, Kolyaie S, Chavoshi SH, Kiavarz Moghaddam H (2008) A SDSS-based earthquake damage assessment for emergency response: case study in Bam. The International Archives of the Photogrammetry, Remote Sensing and Spatial Information Sciences 37 (B8), 451-456.

Theilen-Willige B (2010) Detection of local site conditions influencing earthquake shaking and secondary effects in Southwest-Haiti using remote sensing and GIS-methods. Natural Hazards and Earth System Sciences 10:1183-1196

Thywissen K (2006) Core terminology of disaster reduction: A compartive glossary. In: Birkmann J (ed) Measuring vulnerability to natural hazards. United Nations University Press, New York, pp 448 - 496

Timmermann P (1981) Vulnerability, resilience and the collapse of society. No. 1 in Environmental Monograph. Institute for Environmental Studies, University of Toronto, Canada

Tralli DM, Blom RG, Fielding EJ, Donnellan A, Evans DL (2007) Conceptual case for assimilating interferometric synthetic aperture radar data into the HAZUS-MH earthquake module. IEEE Transactions on geoscience and remote sensing 45:1595-1604

Tralli DM, Blom RG, Zlotnicki V, Donnellan A, Evans DE (2005) Satellite remote sensing of earthquake, volcano, flood, landslide and coastal inundation hazards. ISPRS Journal of Photogrammetry and Remote Sensing 59:185 - 198

Trianni G, Gamba P (2009) Fast damage mapping in case of earthquakes using multitemporal SAR data. Journal of Real-Time Image Processing 4:195-203

Tronin AA (2010) Satellite Remote Sensing in Seismology. A Review. Remote Sensing 2:124-150

Tronin AA (1996) Satellite thermal survey - a new tool for the study of seismoactive regions. Int J Remote Sens 17(8):1439-1455

Tronin AA (2006) Remote sensing and earthquakes: A review. Physics and Chemistry of the Earth 31:138-142

Tsai YB, Liu JY, Ma KF, Yen HY, Chen KS, Chen YI, Lee CP (2006) Precursory phenomena associated with the 1999 Chi-Chi earthquake in Taiwan as identified under iSTEP Program. Phys Chem Earth 31:365377

Turker M, Cetinkaya B (2005) Automatic detection of earthquake-damaged buildings using DEMs created from pre- and post-earthquake stereo aerial photographs. Int J Remote Sens 26(4):823-832

Turker M, San BT (2004) Detection of collapsed buildings caused by the 1999 Izmit, Turkey earthquake through digital analysis of post-event aerial photographs. Int J Remote Sens 25(21):4701-4714

Turker M, Sumer E (2008) Building-based damage detection due to earthquake using the watershed segmentation of the post-event aerial images. Int J Remote Sens 29(11):3073-3089

Turner BL, Kasperson R, Matson P, McCarthy J, Corell R, Christensen L, Eckley N, Kasperson J, Luers A, Martello M, Polsky C, pulsipher A, Schiller A (2003) A framework for vulnerability analysis in 
sustainability science. Proceedings of the National Academy of Sciences of the United States of America 100(14):8074 - 8079

UN (1994) Report of the world conference on natural disaster reduction. Held at Yokohama, Japan, 23-27 May 1994

UN/ISDR (2004) Living with risk: A global review of disaster reduction initiatives. United Nations/International Strategy for Disaster Reduction, Geneva, Switzerland, UN Publications

UN/ISDR (2006) NGOs \& Disaster Risk Reduction: A Preliminary Review of Initiatives and Progress Made. Background Paper for a Consulative Meeting on a "Global Network of NGOs for Community Resilience to Disasters", Geneva, Switzerland, 25-26 October 2006

UN/ISDR (2011) United Nations International Strategy for Disaster Reduction. Available online at http://www.unisdr.org/ Accessed 17 Oct 2011

UNDP (2004) Reducing disaster risk - A challenge for development - A Global report, United Nations Development Programme, New York, USA

UNDP/ERRRP (2009) Earthquake vulnerability profile and preparedness plan of Hetauda municipality. In: Joshi A (ed) Katmandu: United Nations Development Programme/Earthquake Risk Reduction and Recovery Preparedness Programme for Nepal

UNDRO (1979) Natural Disasters and Vulnerability Analysis. Report of Expert Group Meeting, Geneva, Switzerland, 9-12 July 1979

UNOCHA (2012) United Nations Office for the Coordination of Humanitarian Affairs. Available online at http://www.unocha.org/ Accessed 13 Jul 2012

UNOOSA (2011) United Nations office for outer space affairs. Available online at http://www.oosa.unvienna.org/ Accessed 17 Oct 2011

UNOSAT (2011) Unitar's operational satellite applications programme. Available online at http://www.unitar.org/unosat/ Accessed 19 Sep 2011

UN SPIDER (2011) United Nations platform for space-based information for disaster management and emergency response. Available online at http://www.un-spider.org/ Accessed 17 Oct 2011

UR (2012) Understanding Risk - Innovation in Disaster Risk Assessment. Available online at http://www.understandrisk.org/ur/node/4889 Accessed 17 Oct 2011

USGS (2011) Earthquakes with 1,000 or More Deaths since 1900. Available online at http://earthquake.usgs.gov/earthquakes/world/world_deaths.php Accessed 21 Sep 2011

Ushahidi (2012) Ushahidi Platform for information collection, visualization and interactive mapping. Available online at http://ushahidi.com/index.php/products/ushahidi-platform Accessed 12 Jul 2012

van den Broek B, Kiefl R, Riedlinger T, Scholte K, Granica K, Gutjahr K, Stephenne N, Binet R, de la Cruz A (2009) Rapid mapping and damage assessment. In: Jasani B, Pesaresi M, Schneiderbauer S, Zeug G (eds) Remote sensing from space. Supporting international peace and security. Springer, New York, pp $261-286$

van Dillen S (2004) Different choices: assessing vulnerability in South Indian village. Studien zur geographischen Entwicklungsforschung, Verlag für Entwicklungspolitik, vol 9, Saarbrücken, Germany

van Puymbroeck N, Michel R, Binet R, Avouac JP, Taboury J (2000) Measuring earthquakes from optical satellite images. Appl Opt Inf Process 39:1-14

VDV (2012) Virtual Disaster Viewer. Available online at http://vdv.mceer.buffalo.edu/vdv/select_event.php Accessed 21 Sep 2011

Verstappen HT (1995) Aerospace technology and natural disaster reduction. Advances in Space Research 15(11):3-15

Villagrán De Léon JC (2006) Vulnerability: A conceptual and methodological review. SOURCE - Studies of the University: Research, Counsel, Education; UNU Institute for Environment and Human Security (4)

Voigt S, Kemper T, Riedlinger T, Kiefl R, Scholte K, Mehl H (2007a) Satellite image analysis for disaster and crisis-management support. IEEE Transactions on geoscience and remote sensing 45(6):1520 - 1528

Vrijling JK, van Hengel W, Houben RJ (1995) A framework for risk evaluation. Journal of Hazardous Materials 43:245-261

Vu TT, Ban Y (2010) Context-based mapping of damaged buildings from high-resolution optical satellite images. Int J Remote Sens 31 (13):3411-3425

Vu TT, Matsuoka M, Yamazaki F (2004) LiDAR based change detection of buildings in dense urban areas. In: IEEE International Geoscience and Remote Sensing Symposium, September 2004, Anchorage, AK, USA, pp 3413-3416

Vu TT, Matsuoka M, Yamazaki F (2005) Detection and animation of damage using very high-resolution satellite data following the 2003 Bam, Iran, Earthquake. Earthquake Spectra 21:319-327

Walker RT (2006) A remote sensing study of active folding and faulting in southern Kerman province, S.E. Iran. Journal of Structural Geology 28:654-668

Walton M, Bebbington AJ, Dani AA, deHaan A (2008) Institutional pathways to equity: addressing inequality traps. The World Bank, Washington D. C 
Wang C, Zhang H, Wu F, Zhang B, Tang Y, Wu H, Wen X, Yan D (2009a). Disaster phenomena of Wenchuan earthquake in high resolution airborne synthetic aperture radar images. Journal of Applied Remote Sensing 3: 031690 (26 May 2009). doi: 10.1117/1.3154558

Wang FT, Zhou Y, Wang SX, Liu WL, Wei CJ, Han Y (2011) Investigation and assessment of damage in earthquake in Yushu, Qinghai based on multi-spectral remote sensing. Spectroscopy and spectral Analysis 31(4):1047-1051

Wang Z, Xu Q, Xu B, Zhang W (2009b) Emergency aero-photo survey after the 5.12 Wenchuan earthquake, China. Science in China Series E-Technological Sciences 52:835-843

WB/UN (2010) Natural hazards, unnatural disasters: the economics of effective prevention. World Bank/United Nations Washington D.C.

Weston J, Ferreira AMG, Funning GJ (2012) Systematic comparisons of earthquake source models determined using InSAR and seismic data. Tectonophysics 532-535:61-81

White G, Kates R, Burton I (2001) Knowing better and losing even more: the use of knowledge in hazards management. Environmental Hazards 3:81-92

White P, Pelling M, Sen K, Seddon D, Russell S, Few R (2005) Disaster risk reduction: a development concern. A scoping study on links between disaster risk reduction, poverty and development. Department for International Development

Whitman RV (1973) Damage probability matrices for prototype buildings. Structures Publication. Department of Civil Engineering, Massachusetts Institute of Technology, Boston, Massachusetts, USA

Wieland M, Pittore M, Parolai S, Zschau J, Moldobekov B, Begaliev U (2012) Estimating building inventory for rapid seismic vulnerability assessment: Towards an integrated approach based on multi-source imaging. Soil Dynamics and Earthquake engineering 36:70-83

Wisner B (2004) Assessment of capability and vulnerability. In: Bankoff G, Frerks G, Hilhorst D (eds) Mapping vulnerability. Disasters, Development \& People. Earthscan, London, pp 183 - 205

Wisner B (2007) Regions at risk or people at risk? Wie natürlich sind "Naturkatastrophen"? Geographische Rundschau 59(10):256 - 276

Wisner B, Blaikie P, Cannon T, Davis I (2003) At risk: natural hazards, people's vulnerability and disasters. 2 edn. Routledge, London \& New York

Wolf S (2011) Vulnerability and risk: comparing assessment approaches. Natural Hazards. doi: 10.1007/s11069011-9968-4

Wyss M (2004) Real-time prediction of earthquake casualties. In: Malzahn D, Plapp T (eds) Disasters and society - From hazard assessment to risk reduction. Logos Publishers, Conference proceedings, Karlsruhe, Germany, pp 165-173, 26-27 July 2004

Wyss M, Wang R, Zschau J, Xia Y (2006) Earthquake loss estimates in near-real time. EOS Transactions American Geophysical Union 87(44):477-492

Wyss M (2012) Mapping Seismic Risk: The current crisis. Taubenböck H, Post J, Strunz G (eds.) Remote Sensing contributing to mapping earthquake vulnerability and effects. Special Issue in Natural Hazards. To be published.

Xu W, Dong R, Wang X, Ouyang Z, Li Z, Xiao Y, Zhang J (2009) Impact of China's May 12 earthquake on Giant Panda habitat in Wenchuan County. Journal of Applied Remote Sensing, 3: 031655 (26 May 2009). doi: 10.1117/1.3153916

Yamazaki F, Kouch K (2006) Automated damage detection of buildings from high-resolution satellite images. Paper presented at the First European Conference on Earthquake Engineering and Seismology, September 2006, Geneva, Switzerland, pp 3-8

Yamazaki F, Matsuoka M (2007) Remote sensing technologies in post-disaster damage assessment. Journal of Earthquake and Tsunami 1(3):193-210

Yang Y, Guo G (2010) Studying the thermal anomaly before the Zhangbei earthquake with MTSAT and meteorological data. International Journal of Remote Sensing 31:2783-2791

Yano Y, Yamazaki F (2006) Building damage detection of the 2003 Bam, Iran earthquake using Quickbird images based on object-based classification. Proceedings, Asian Conference on Remote Sensing, Ulaanbaatar, Mongolia

Yen J-Y, Chen K-S, Chang C-P, Boerner W-M (2008) Evaluation of earthquake potential and surface deformation by differential interferometry. Remote Sensing of Environment 112:782-795

Yodmani S (2001) Disaster Risk Management and Vulnerability Reduction: Protecting the Poor. Paper presented at the Asia Pacific Forum on Poverty; Organized by the Asian Development Bank

Yong A, Hough SE, Abrams MJ, Cox HM, Wills CJ, Simila GW (2008a) Site Characterization Using Integrated Imaging Analysis Methods on Satellite Data of the Islamabad, Pakistan, Region. Bulletin of the Seismological Society of America 98(6):2679-2693

Yong A, Hough SE, Abrams MJ, Wills CJ (2008b) Preliminary results for a semi-automated quantification of site effects using geomorphometry and ASTER satellite data for Mozambique, Pakistan, Turkey. J. Earth Syst. Sci. 117(S2):797-808 
Yu H, Zhao Y, Ma Y, Sun Y, Zhang H, Yang S, Luo Y (2011) A remote sensing-based analysis on the impact of Wenchuan Earthquake on the core value of World Nature Heritage Sichuan Giant Panda Sanctuary. Journal of Mountain Science 8:458-465

Yurur MT (2006) The positive temperature anomaly as detected by Landsat TM data in the eastern Marmara Sea (Turkey): possible link with the 1999 Umit earthquake. International Journal of Remote Sensing 27:1205-1218

Zeng J, Zhu ZY, Zhang JL, Ouyang TP, Qiu SF, Zou Y, Zeng T (2012) Social vulnerability assessment of natural hazards on county-scale using high spatial resolution satellite imagery: a case study in the Luogang district of Guangzhou, South China. Environ Earth Sci 65:173-182

Zhang J, Zhou C, Xu K, Watanabe M (2002) Flood disaster monitoring and evaluation in China. Global Environmental Change Part B: Environmental Hazards 4:33-43

Zhang K, Ng AHM, Ge L, Dong Y, Rizos C (2010) Multi-path PALSAR interferometric observations of the 2008 magnitude 8.0 Wenchuan Earthquake. International Journal of Remote Sensing 31:3449-3463

Zschau J, Isikara M, Ergünay O, Yalcin M N, Erdik M. (2002) Towards an earthquake early warning system for themegacity Istanbul. Early Warning Systems for Natural Disaster Reduction, edited by Zschau J and Küppers A, pp.433-440, Springer. 